نحو تطبيق اللامركزية فى الوحدات المحلية بريف محافظة المنيا :التحديات و المعوقات

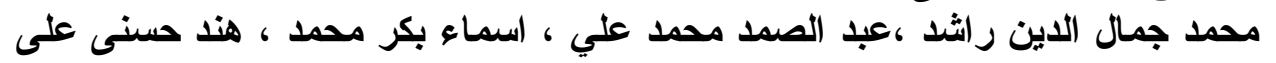

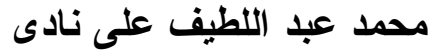

$$
\begin{aligned}
& \text { قسم المجتمع الريفى والإرشاد الزرعى - كلية الزر اعة - جامعة أسيوط }
\end{aligned}
$$

Received on: $17 / 3 / 2016$

Accepted for publication on: 31/3/2016

ملخص البحث

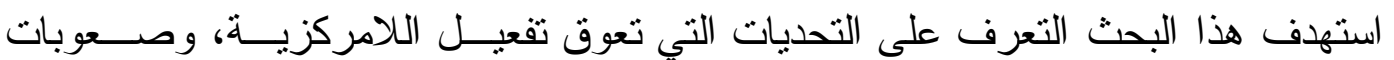

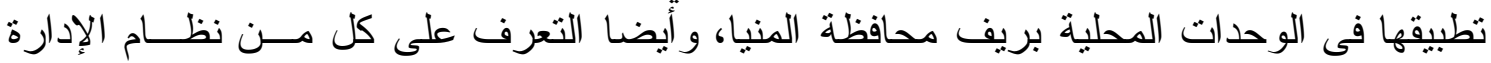

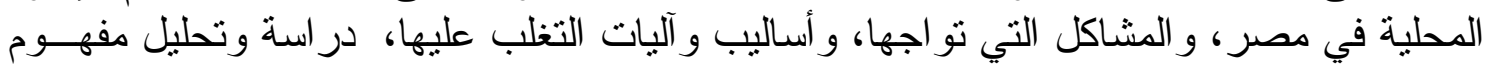
اللامركزية بإبعادها المختلفة، و الوقوف النق على أهم اليجابيات وسلبيات تطبيقها.

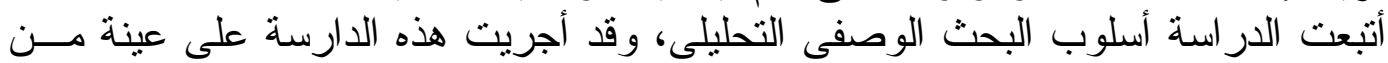

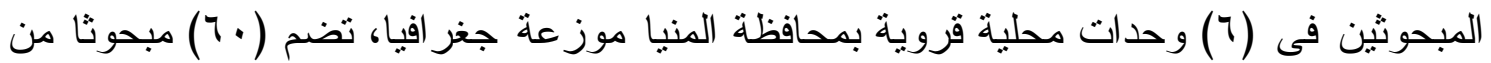

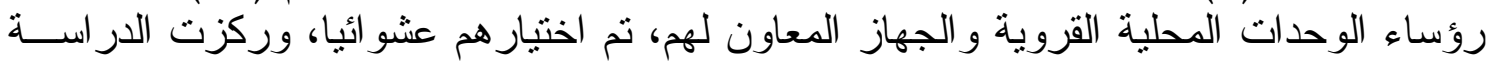

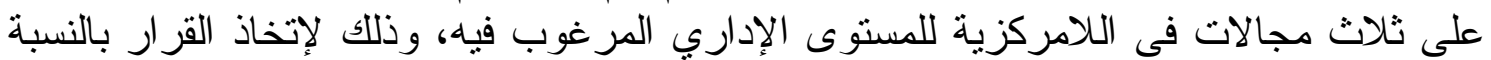

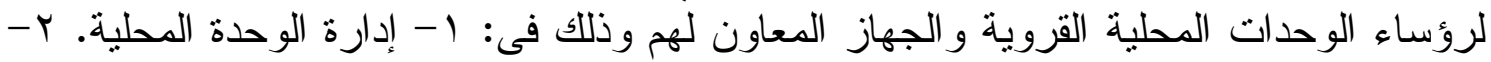

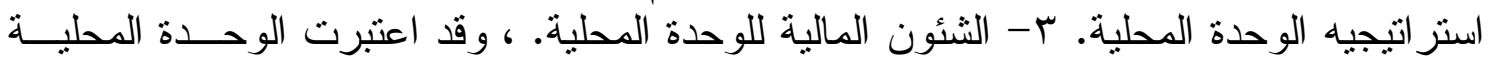

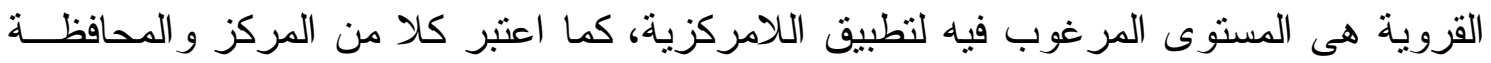
المستوى المرغوب فيه للتطبيق المركزية.

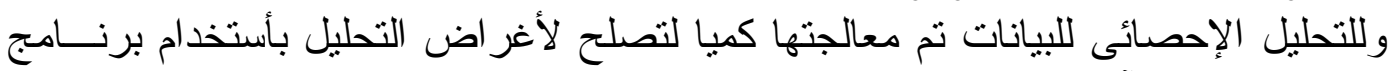
عPSS

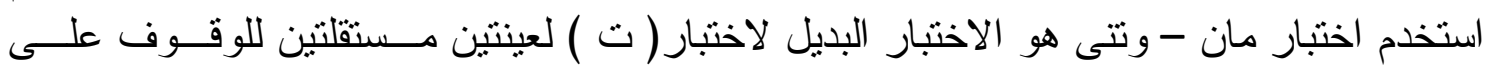

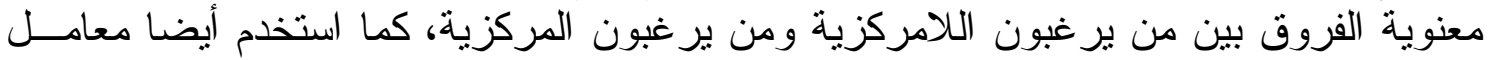

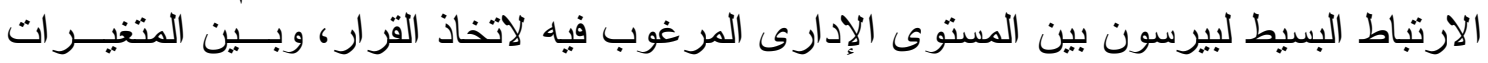

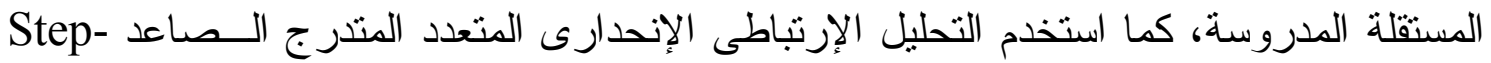

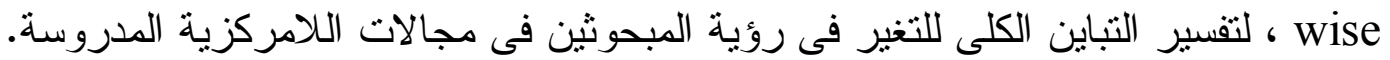

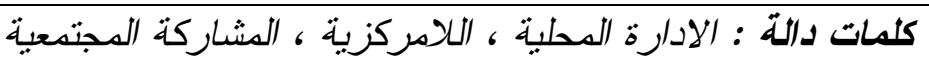

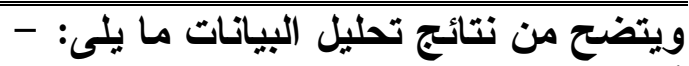
أولا: وصف البيانات

1 إبلغت نسبة من يفضلون نظام اللامركزية في إدارة الوحدة المحلية و الذى يمتلكه القرية

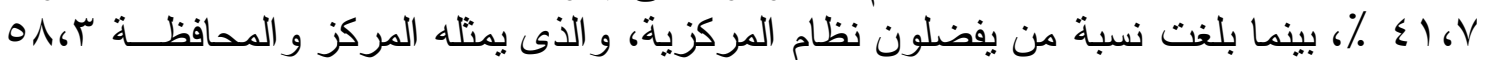

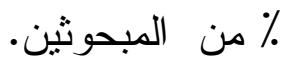

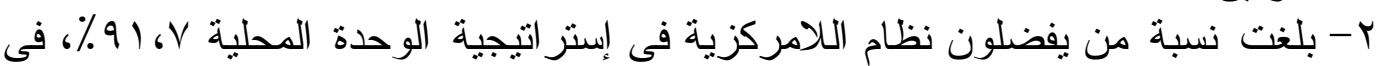

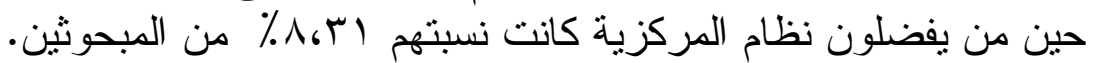

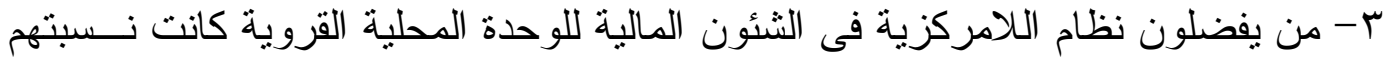

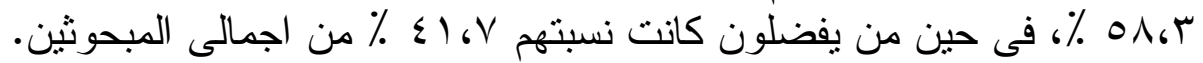

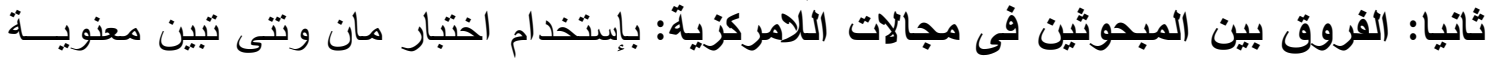

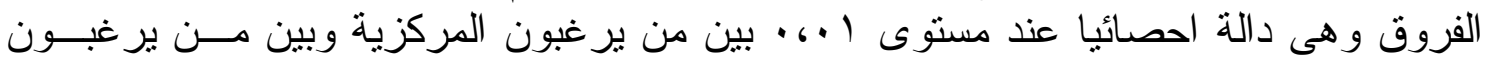

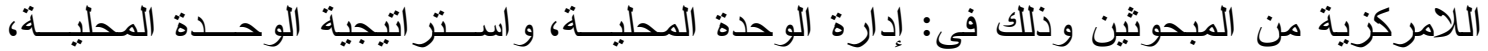

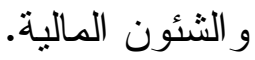


ثالثا: العلاقات الإرتباطية المعنوية: بإستخدام معامل الارنباط البسيط لبيرسون وجــود علاقــات

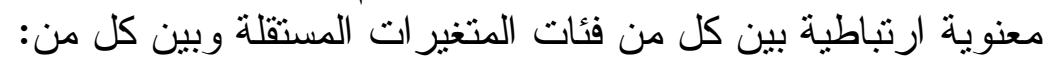

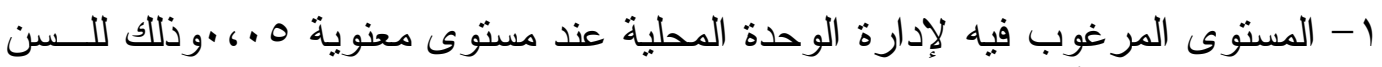

و الحالة الزو اجية وحجم الأسرة و المعوقات فئ لإدة المالية.

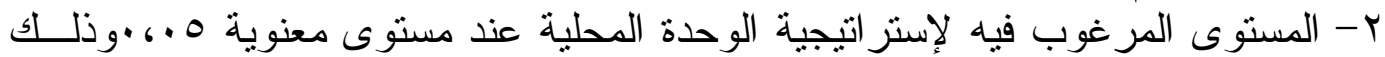

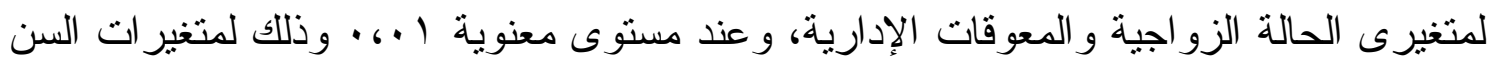
و أهمية اللامركزية و المعوقات النتظيمية.

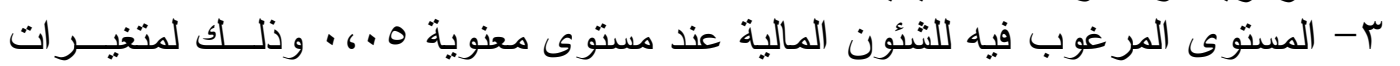

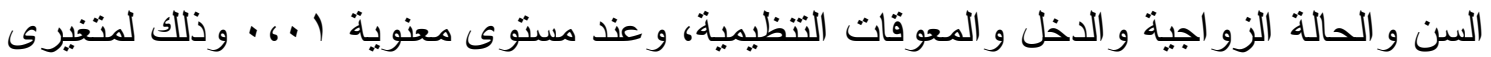
خبرة العمل و أهمية اللامركزية.

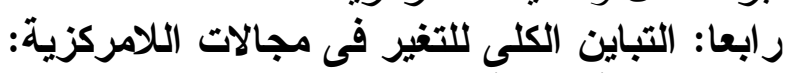

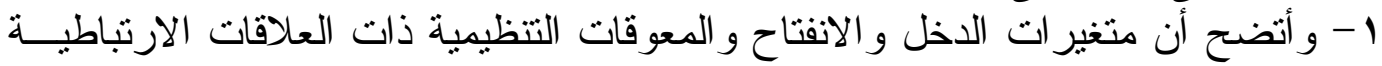

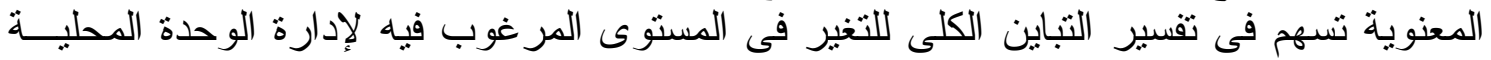

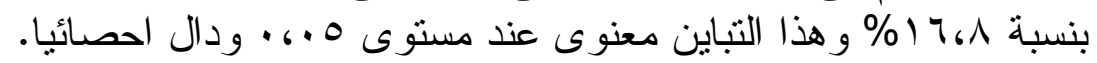

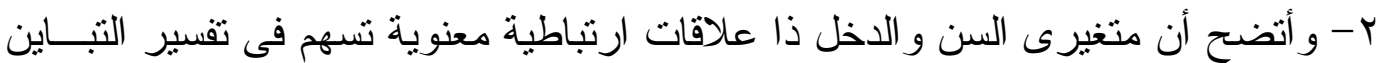

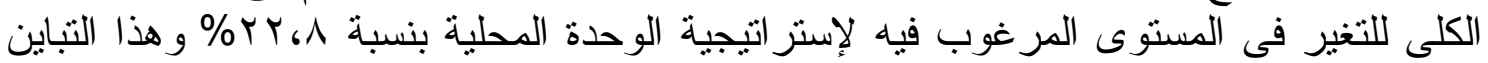

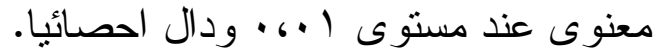

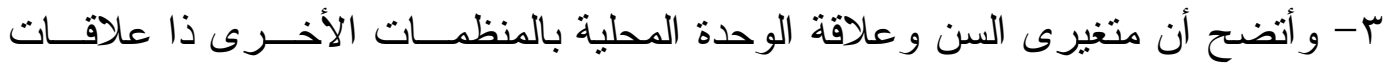

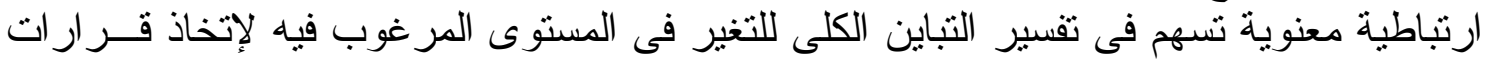

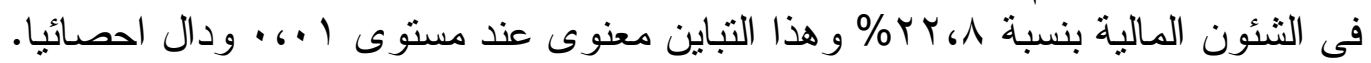
وقد تضمنت الدر اسة مجموعة من التوصيات من أهمها:

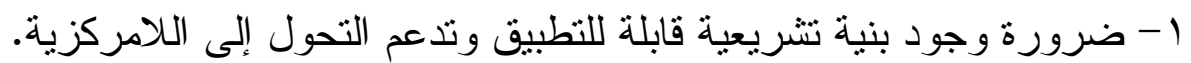

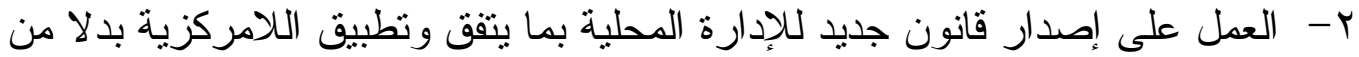

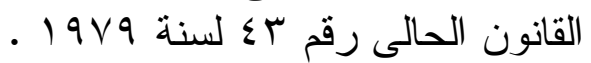

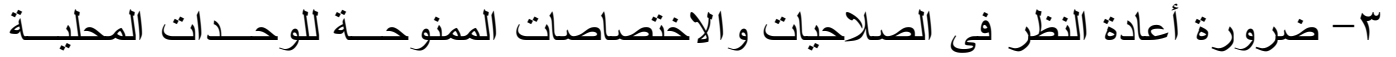

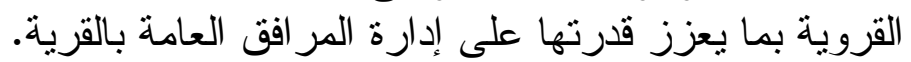

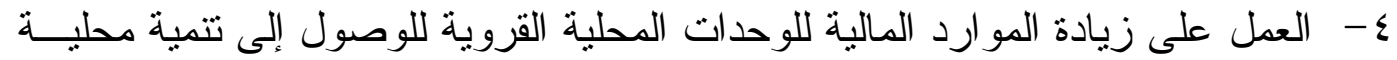
شاملة ه- الاستمر ار فى محاو لات رفع كفاءة الجهاز الإدارى و إعداد كو ادر بشرية مؤهلة للقيام بالعمل الإدارى بأسلوب اللامركزية على أكمل وجهة. المقدمة و المشكلة الأديا

يستهدف النظام المحلي أساسا إلى تقريب السلطة دن المو اطن، و إثنر اكه في اتخاذ قراره

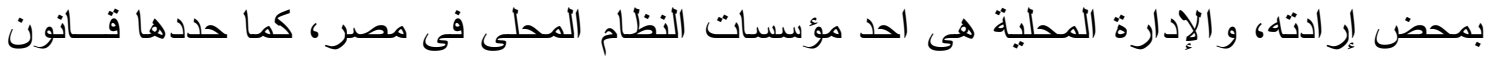

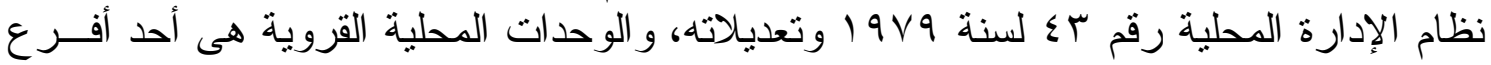

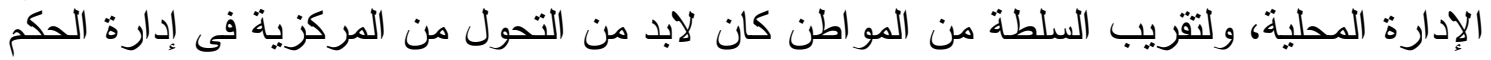

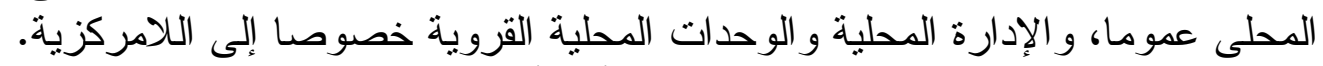

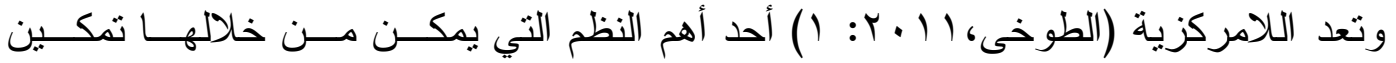

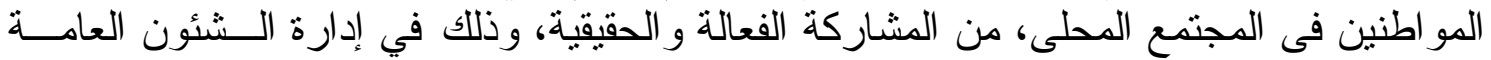

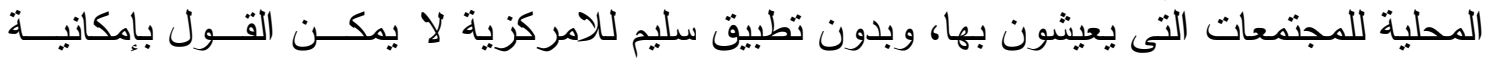

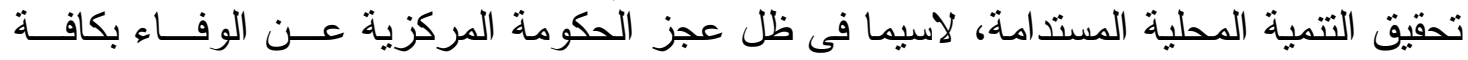

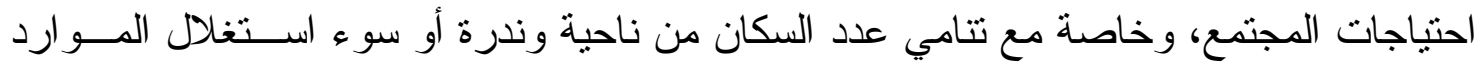




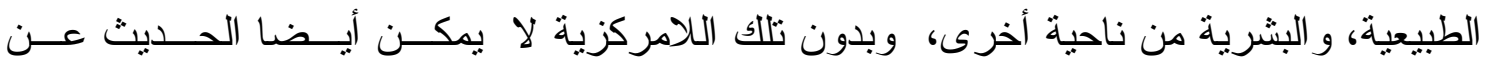
الديمقر اطية بأثكالها المختلفة؟، وخاصة السية السياسية و الإدارية.

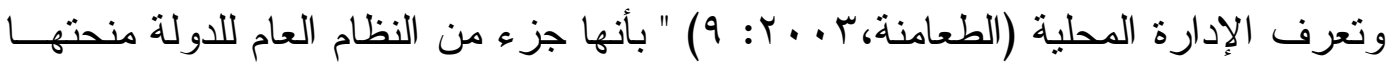

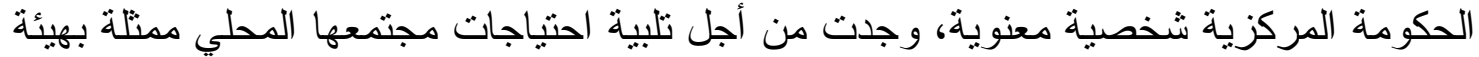

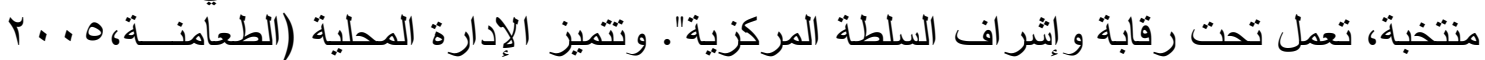

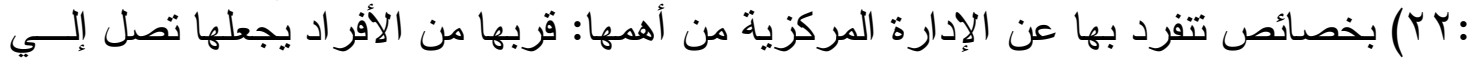

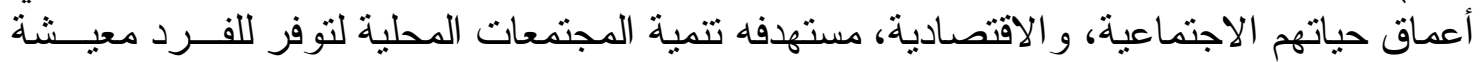

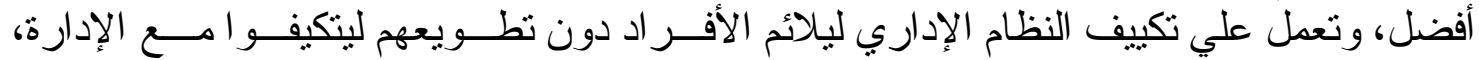

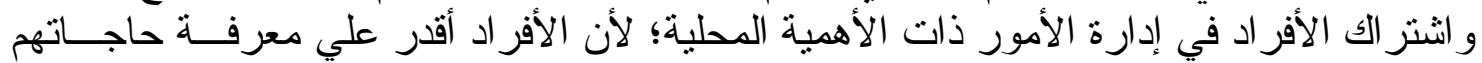

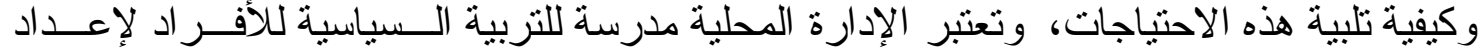

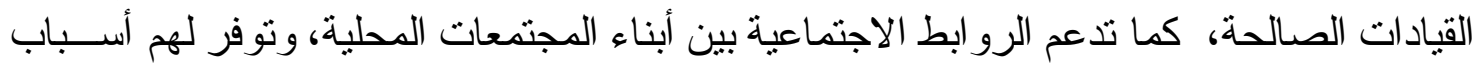

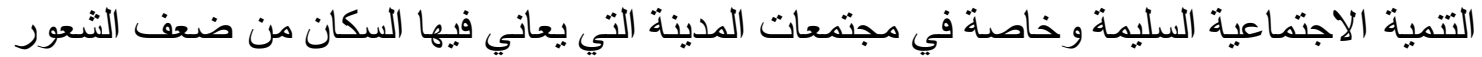

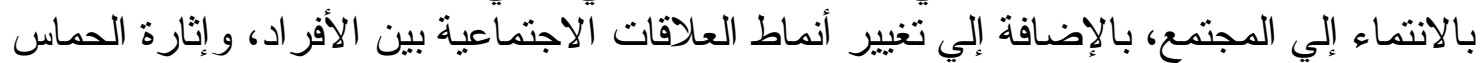

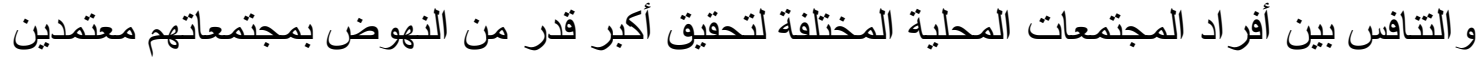
في ذللك علي جهودهم الذاتية.

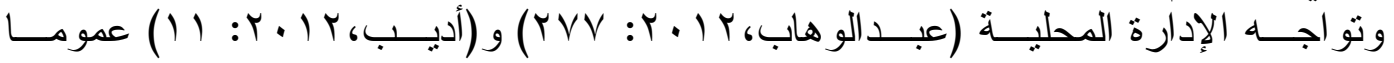

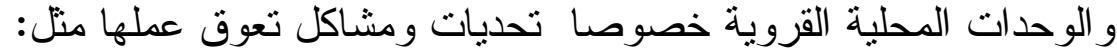

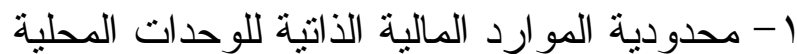

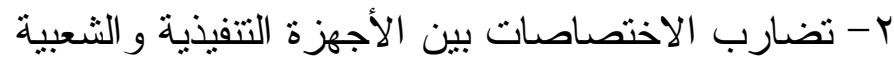

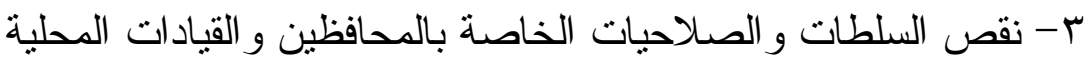
ع - التبعية المزدوجة لمديريات الخدمات ه- غياب دور الإدارة المحلية في قيادة التتمية الاقتصادية المحلية

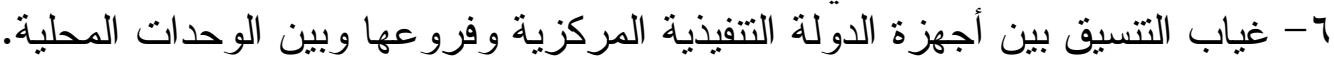

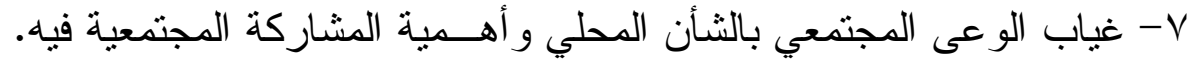

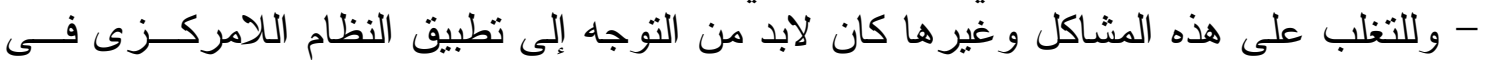
الإدارة المحلية وفرو عها المختلفة.

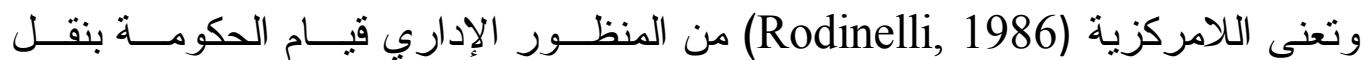

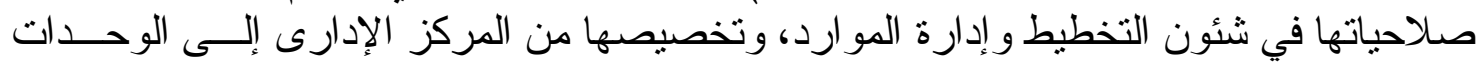

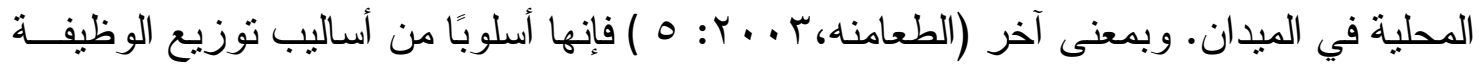

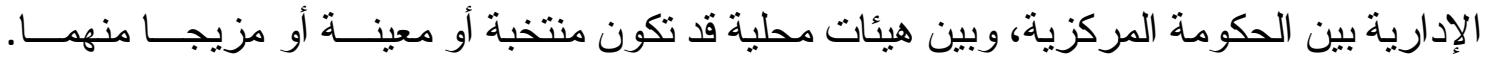

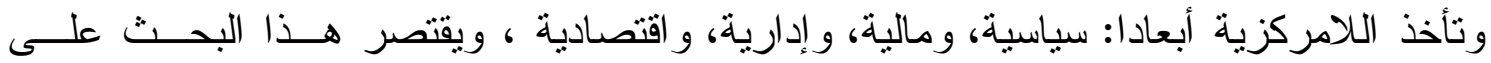

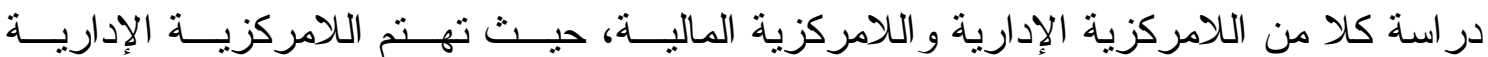

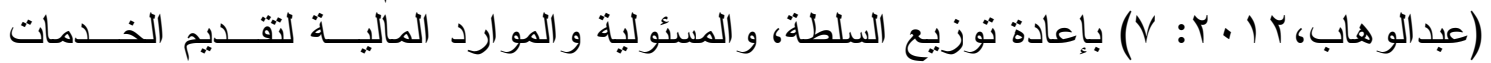

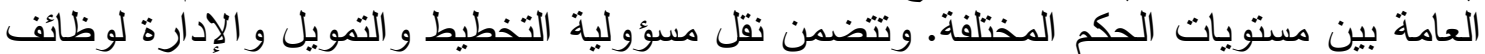

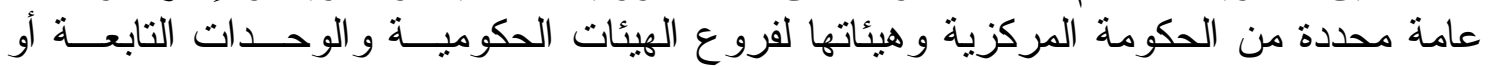

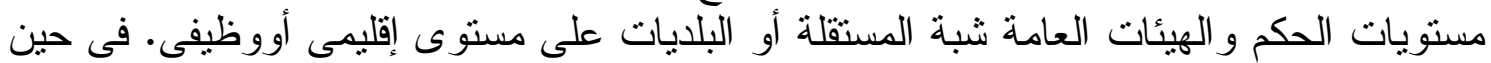

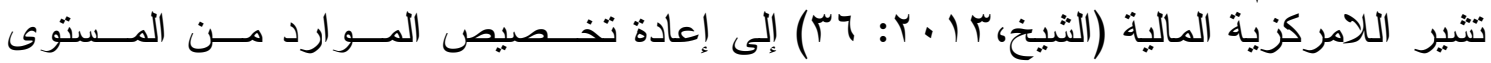

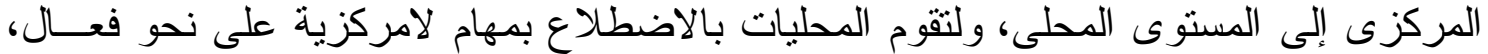
يجب أن يكون لها اير ادات كافيه، فضلا عن سلطة اتخاذ القرار اتل بشان لإنان النفقات. 


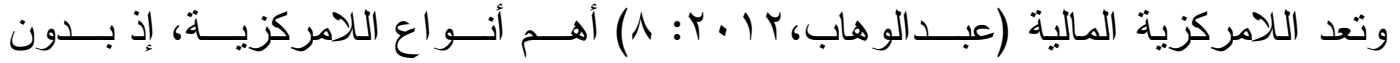

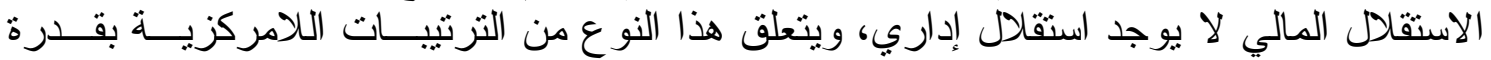

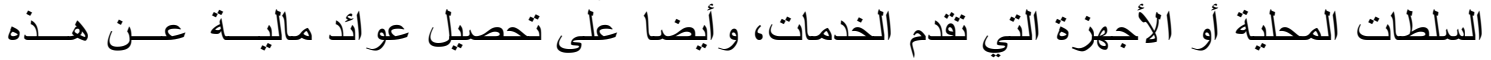

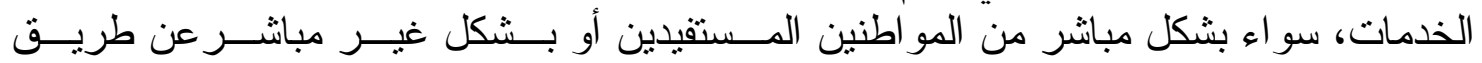

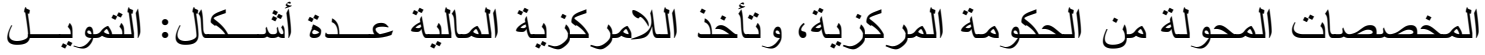

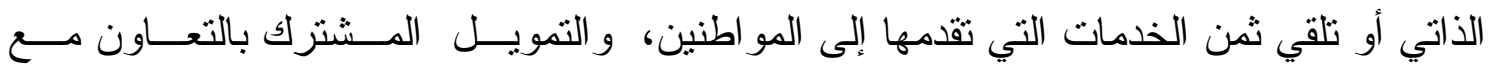
المستقيدين الذين يقدمون مقابلا عينياً للخدمات التي يحصلون عليها، وزيادة المردود المالي مسنـن

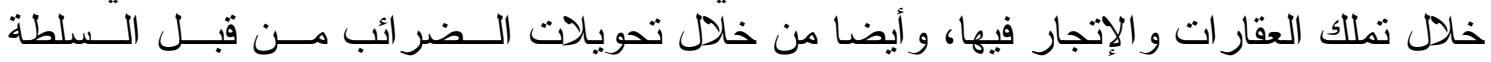

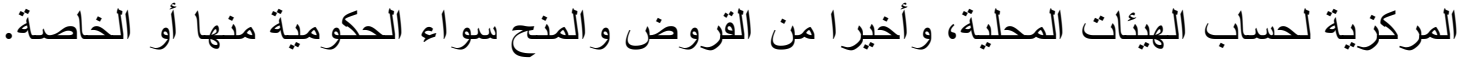

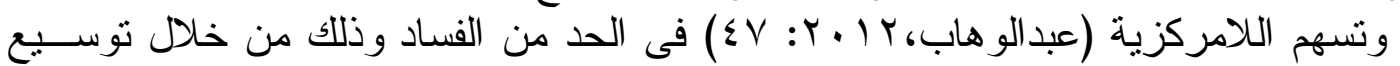
فرص مشاركة المو اطنين، وفى إعداد الخطة و الموازنة على المستوى المحلى (الخطة و الموازنة

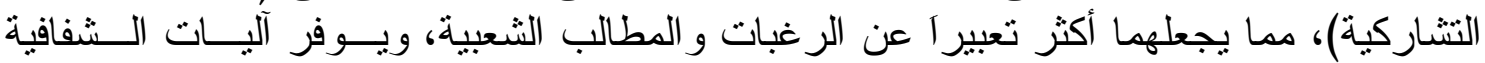
المالية داخل الوحدات المحلية.

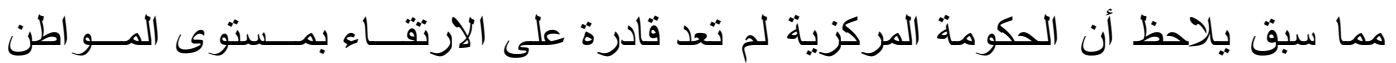

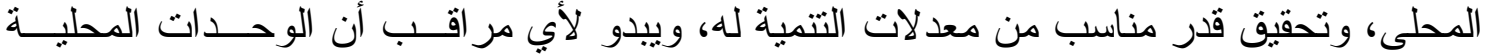

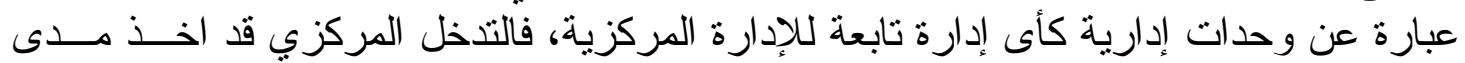

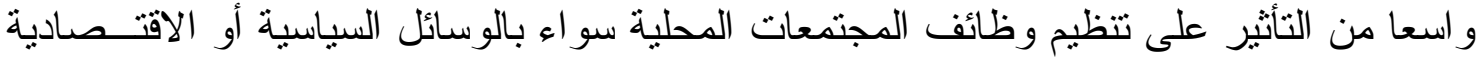

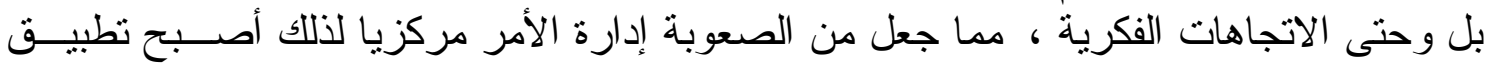

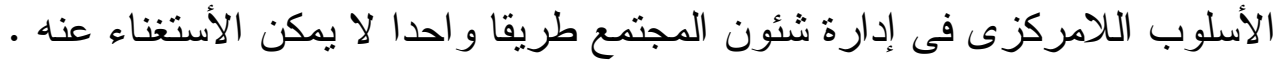

المشكلة البحثية

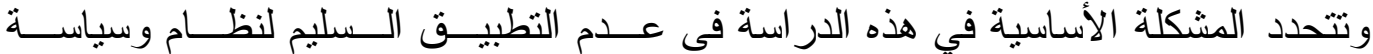

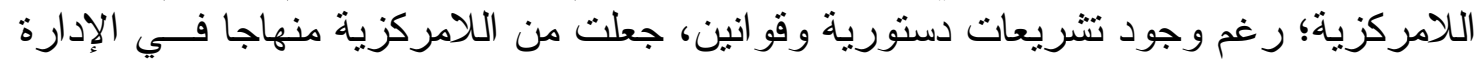

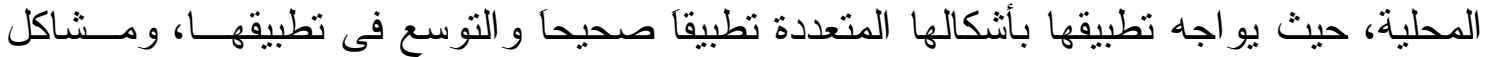

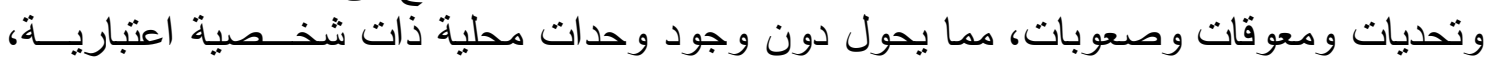

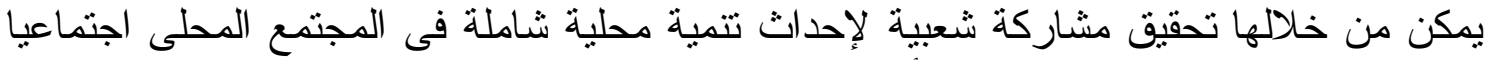

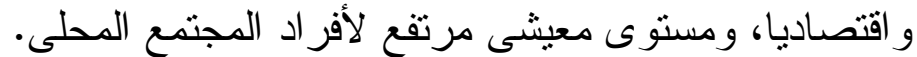

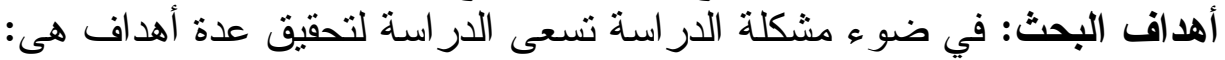
1 - التعرف على نظام الإدارة المحلية في مصر ، و المشاكل التي تو اجها، و أساليب و آليات

التغلب عليها.

ب- التعرف على التحديات التي تعوق تفعيل اللادركزية في الوحدات المحليــة بمحافظـــة المنيا.

ب- تحديد أساليب و آليات تفعيل اللادركزية في الوحدات المحلية القروية.

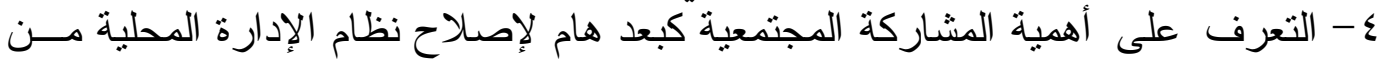

خلال تفعيل نظام اللامركزية في الإدارة المحلية. الفروض البحثية: فى ضوء مشكلة و أهداف الدارسة تم صياغة الفروض البحثية التالية :

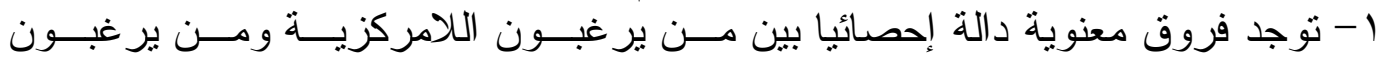

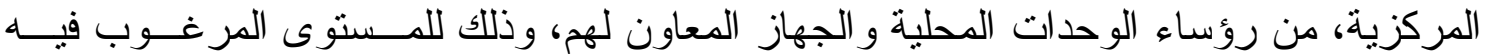

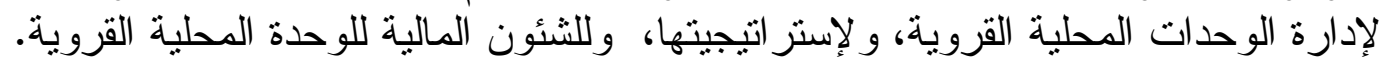

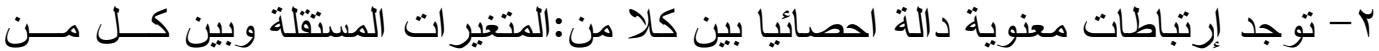

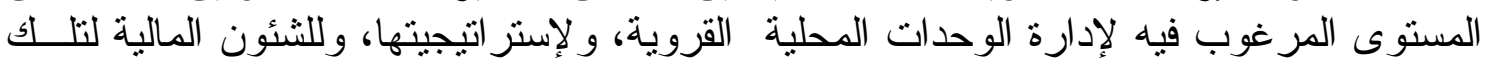
الوحدات المحلية القروية. 


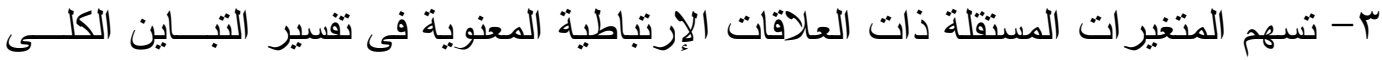

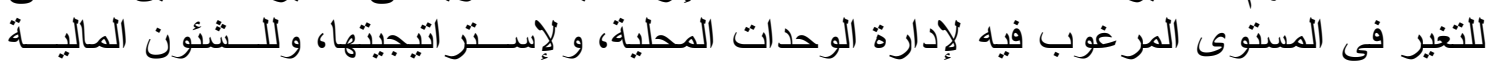
اللوحدات المحلية القروية. الطريقة البحثية وعينة الدراسة التية

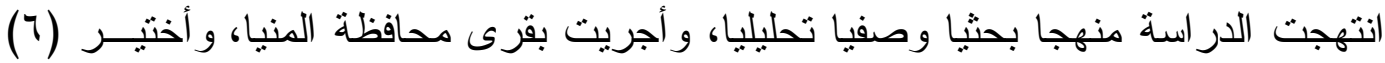

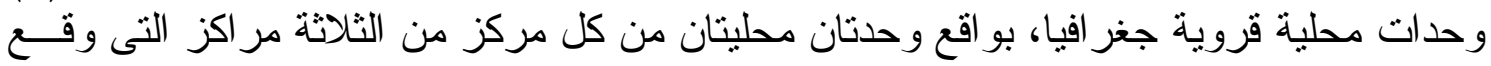

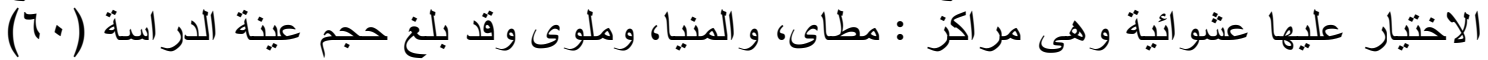

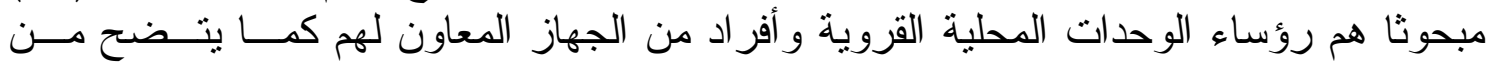

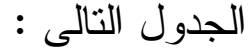

جدول رقم (1):التوزيع العددى عينة الدراسة و الوحدات المحليــة القرويــة محسلـ الدراســة و والمر اكز التابع لهاب العائ

\begin{tabular}{|c|c|c|c|c|}
\hline عدد القرى التوابع & موقعها من المركز & الوحدة المحلية القروية & المركز & م \\
\hline 0 & شرق & أبو عزيز & \multirow{2}{*}{ مطاى } & \multirow{2}{*}{1} \\
\hline 7 & غرب & بردنو ها & & \\
\hline$\wedge$ & شرق & بني محمد سلطان & \multirow{2}{*}{ 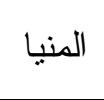 } & \multirow{2}{*}{$r$} \\
\hline$r$ & غرب & بني احمد الغربية & & \\
\hline$\varepsilon$ & شرق & الروضة & \multirow{2}{*}{ ملوي } & \multirow{2}{*}{$r$} \\
\hline 9 & غرب & دروة & & \\
\hline
\end{tabular}

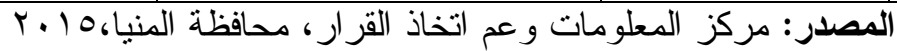

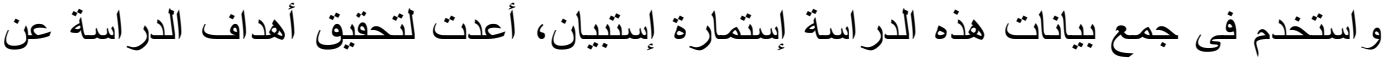

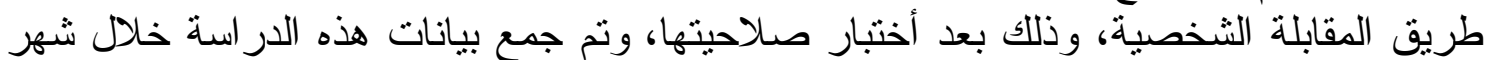

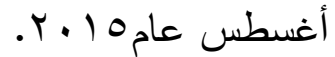
المتغيرات: وقد تضمنت استمارة الاستبيان البيانات التالية:

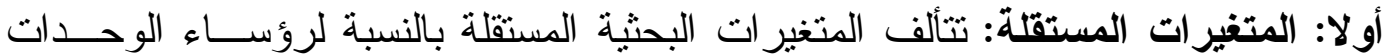

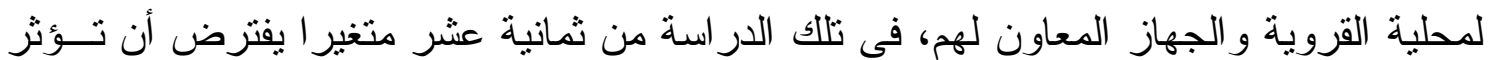

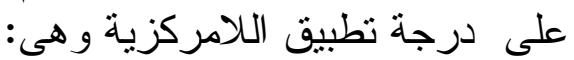

$$
\begin{aligned}
& \text { r } \\
& \text { ع - الحالة الوظيفية } \\
& \text { 4- 1 - محل لميلاد } \\
& \text { 1- حجم الأسرة } \\
& \text {. } \\
& \text { r ا - العضوية في المنظمات }
\end{aligned}
$$

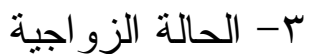
0- - - - محل الإقامة

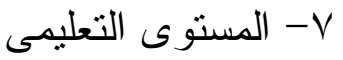

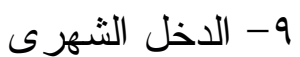

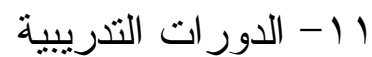

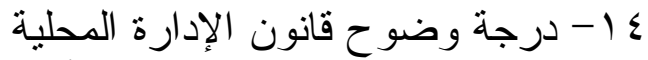

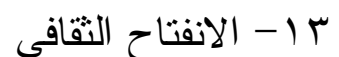

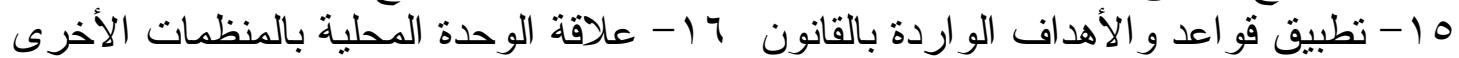

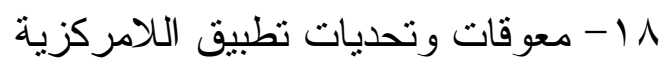
lV

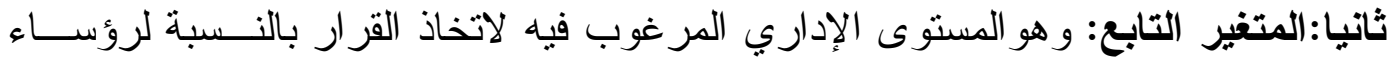

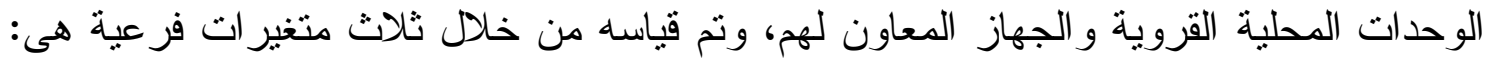

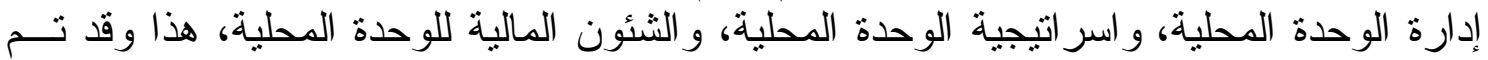

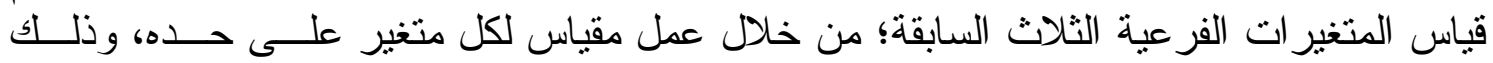


بإعطاء وزنا لكل مستوى إدارى مرغوب فيه؛ فالمستوى اللامركزى وتمثله القرية أعطى وزنـــا

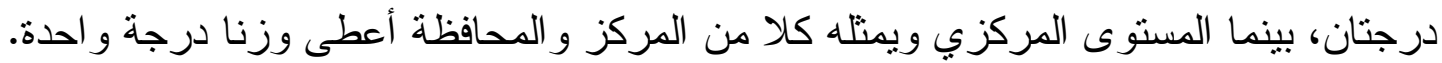
الفروض الإحصائية: فى ضوء مشكلة و أهداف الدارسة تم صياغة الفروض البحثية التالية :

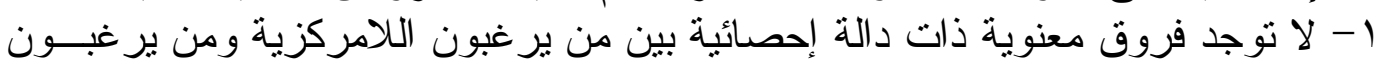

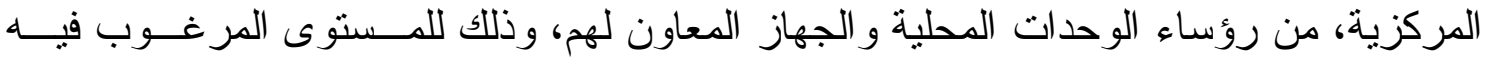

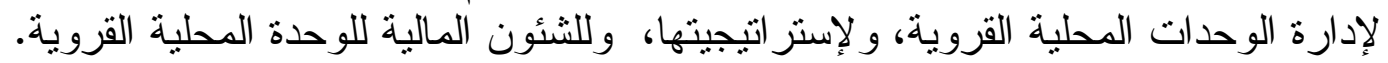

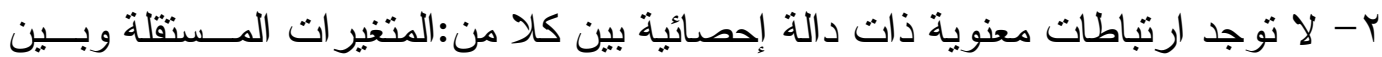
كل من المستوى المرغوب فيه لإدارة الوحدات المحلية القروية، و لإستر اتيجيتها، وللشئونئون المالية لتلك الوحدات المحلية القروية. ب- لا تسهم المتغير ات المستقلة ذات العلاقات الإرتباطية المعنوية فى تفسير التباين الكلى رؤى

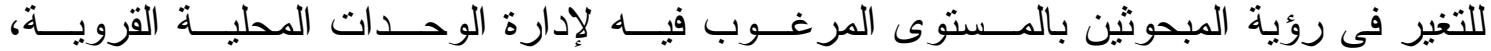

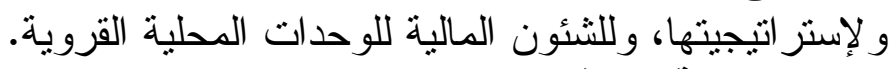

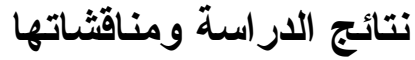

بعد تحليل البيانات وجدولتها فى جداول أعدت لهذا الغرض، تقدام الصفحات التالية عرضا

و افيا لنتائج الدر اسة ومناقتناتها من خلال الصفحات الصات التالية: أولا: وصف البيانات و الفروق بين المبحوثين في مجالات التهات اللادركزية: ثنانيا: الفروق بين المبحوثين فى مجالات اللامركزية:

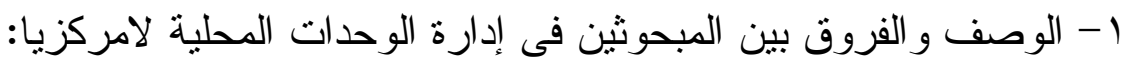

جدول رقم (ץ): التوزيع العددى والنسبى واختبار مان وتنى لرؤساء الوحدات المحلية والجهاز

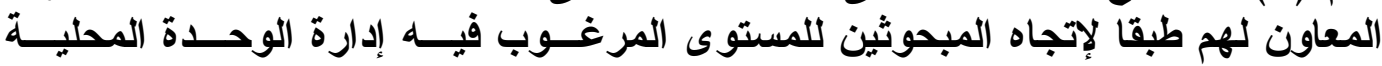

\begin{tabular}{|c|c|c|c|c|}
\hline الدلالة & اختبار مان وتنى " Z" & $\%$ & التكر ار & إدارة الوحدة المحلية \\
\hline \multirow{3}{*}{ دال } & \multirow{3}{*}{ 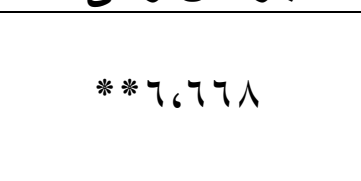 } & $\sum 1, V$ & ro & لا مركزية (القرية) \\
\hline & & $0 \Lambda_{6} \mathrm{~K}$ & ro & مركزية (المركز - المحافظة ) \\
\hline & & $1 \cdots$ & 7. & الاجمالىى \\
\hline
\end{tabular}

**** دال عند مستوى معنوية ( +.،

مصدر البيانات: استمارة الآستبيان

يتبين من نتائج الجدول رقم (Y) أن من يفضلون نظام اللادركزية فى إدارة الوحدة المحلية

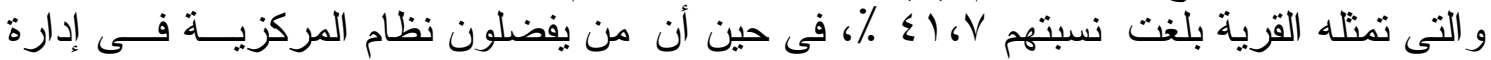

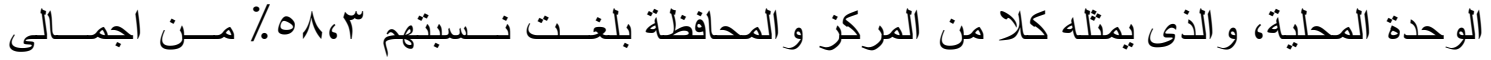

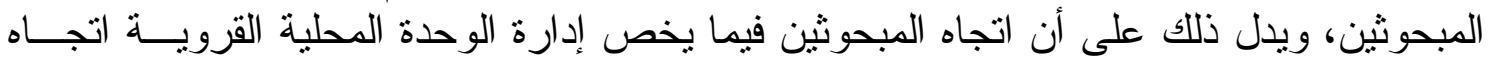

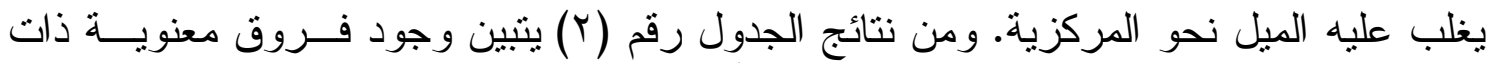

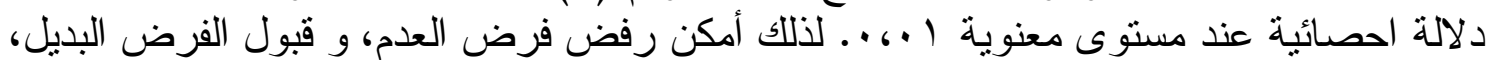

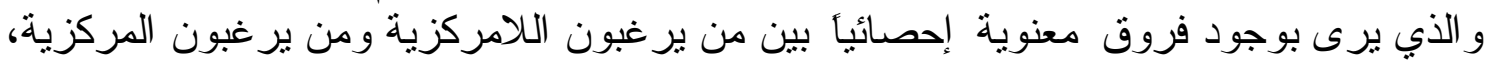

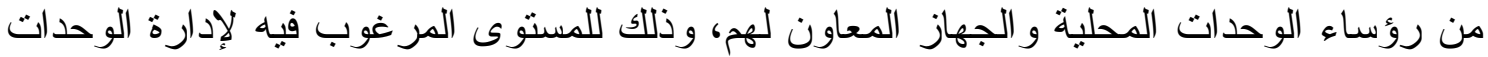
المحلية القروية.

r- الوصف والفروق بين المبحوثين فى إستر اتيجية الوحدة المحلية لامركزيا:

جدول رقم (ب): التوزيع العددى والنسبى واختبار مان وتنى لرؤساء الوحدات المحلية والجهاز

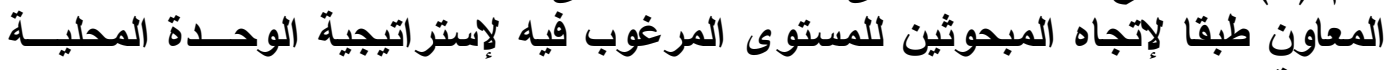
القروية المعاونة

إستر اتيجية الوحدة المحلية




\begin{tabular}{|c|c|c|c|c|}
\hline \multirow{3}{*}{ 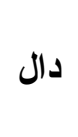 } & \multirow{3}{*}{$* * \mu_{6} \wedge \cdot \Lambda$} & 91.6 & 00 & لا مركزية (القريةة) \\
\hline & & $\Lambda_{6} r$ & 0 & مركزية ( المركز - المحافظة ) \\
\hline & & $1 \ldots$ & 7. & الاجمالى \\
\hline
\end{tabular}

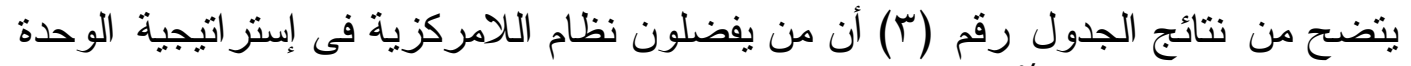

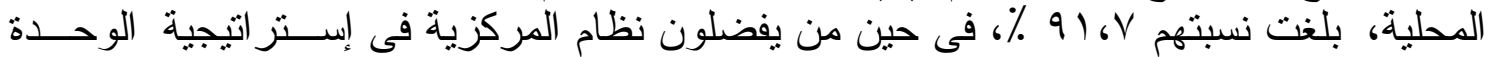

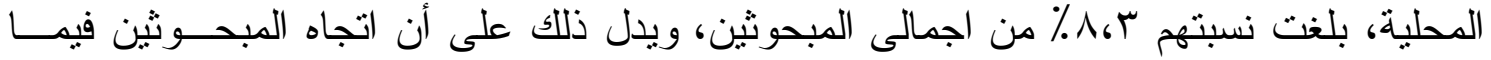

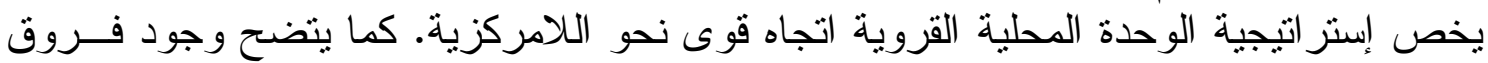

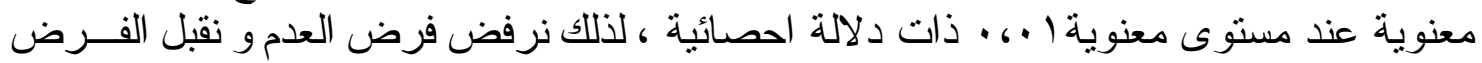

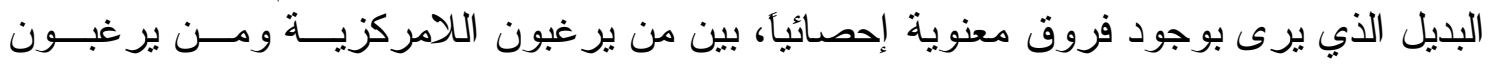

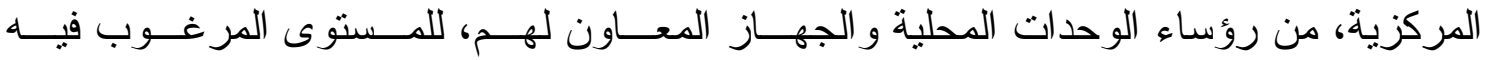
لإستر اتيجية الوحدة المحلية القروية. r- الوصف و الفروق الفروق بين المبحوثن فى الثئون المالية لامركزيا:

جدول رقم (؛ ): التوزيع العددى والنسبى واختبار مان وتنى لرؤساء الوحدات المحلية والجهاز

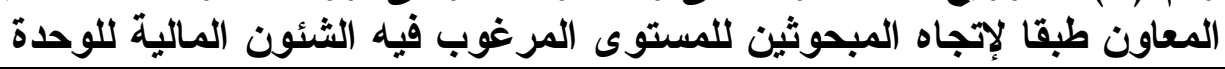

\begin{tabular}{|c|c|c|c|c|}
\hline 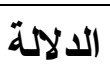 & "Z " اختبار مان وتنى & $\%$ & التكر ار & الثئون المالية \\
\hline \multirow{3}{*}{ دال } & \multirow{3}{*}{$* * 7_{6} 7.0$} & $0 \Lambda_{6}, \pi$ & ro & لا مركزية ( القرية ) \\
\hline & & $\sum 16 V$ & ro & مركزية ( المركز - المحافظة ) \\
\hline & & $1 \ldots$ & 7. & الاجمالى , \\
\hline
\end{tabular}

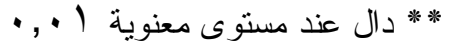

مصدر البيانات: استمارة الآستبيان

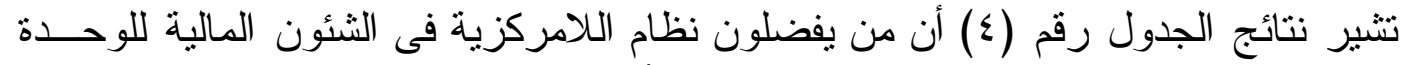

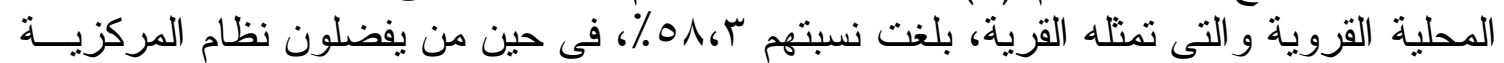

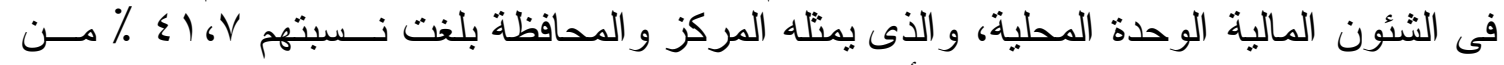

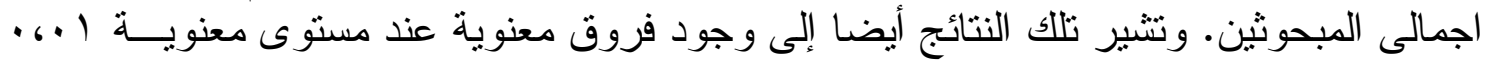

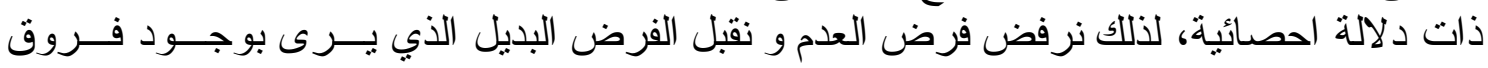

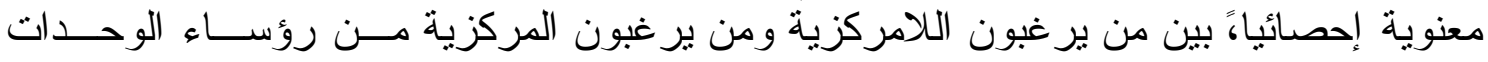
المحلية والجهاز المعاون لهم، للمستوى المر غوب فيه للثئون المالية للوحدة المحلية القرية القروية.

ثانيا:العلاقات الارتباطية بين مجالات اللامركزية وبين المتغيرات المستقلة المدروسة: جدول (ه): قيم معامـل الارتبــاط البـسيط لبيرســون بــين درجــات المسـستوى الإدارى

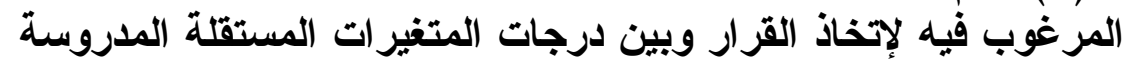

\begin{tabular}{|c|c|c|c|}
\hline الشئون المالية & إستر اتيجية الوحدة & إدارة الوحدة & المتغيرات المستقلة \\
\hline *. GYVO & 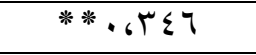 & $\because \cdot 6 r 90$ & السن \\
\hline *.6Y१Y- & *.6TVI- & *.6 & الحالة الزواجية \\
\hline - & - & $* .6990$ & حجم الأسرة \\
\hline$* \cdot 6 r \cdot 9$ & - & - & الدخل \\
\hline 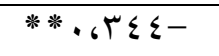 & - & - & خبرة العمل \\
\hline 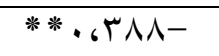 & $* *$ * $60 .-$ & - & إجمالى أهمية الللامركزية \\
\hline- & 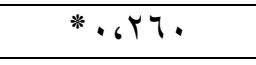 & - & المعوقات الإدارية \\
\hline- & - & \& & المعوقات المالية \\
\hline
\end{tabular}




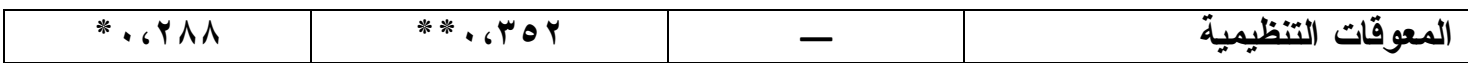

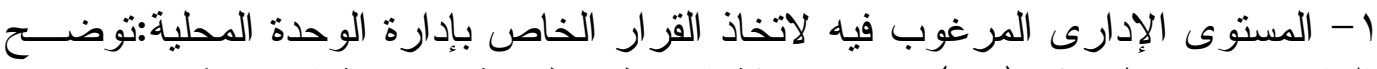
النتائج الواردة فى جدول رقم (

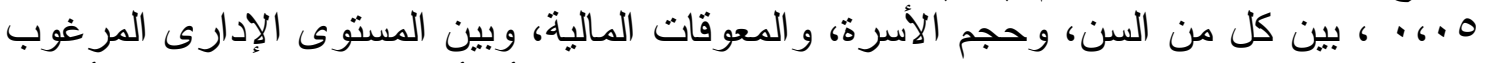

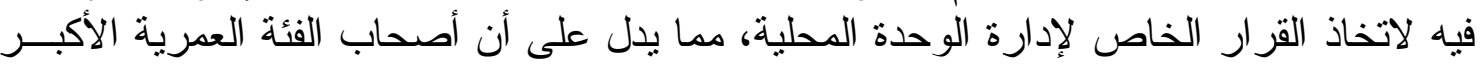

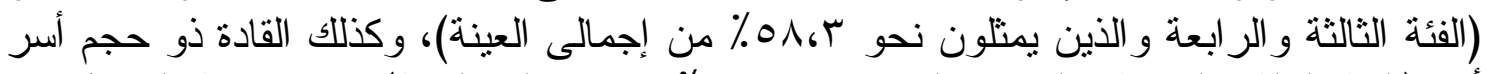

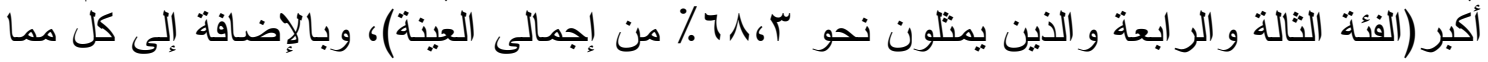

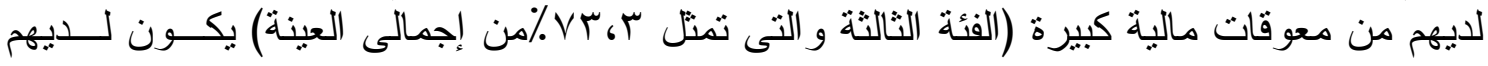
اتجاه يغلب عليه الميل نحو اللامركزية فى القرار ات الفات الخاصة بإدارة الوحدة المحلية .

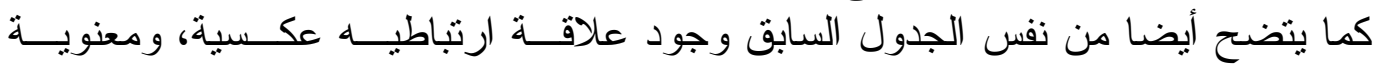

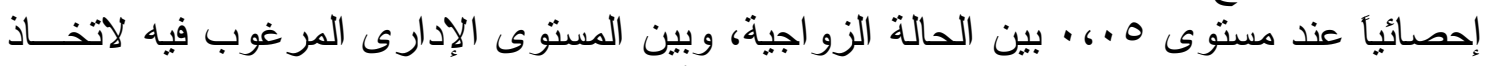

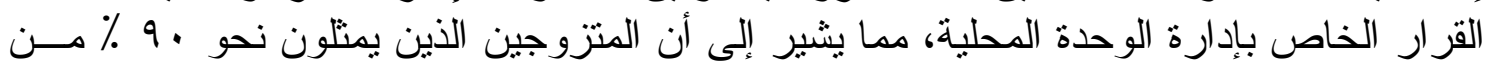

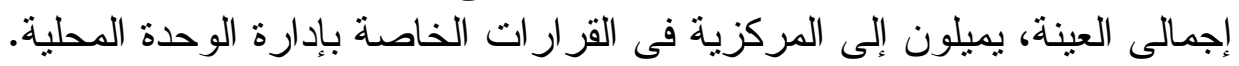

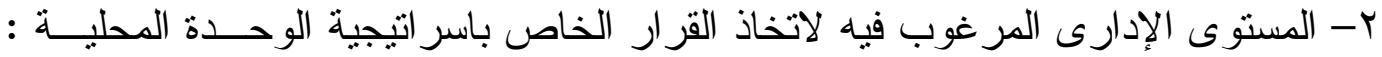

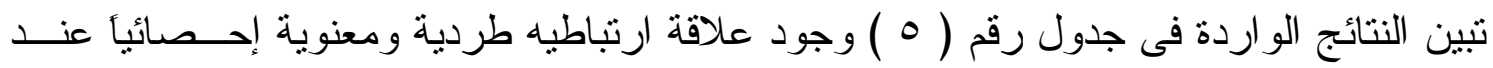

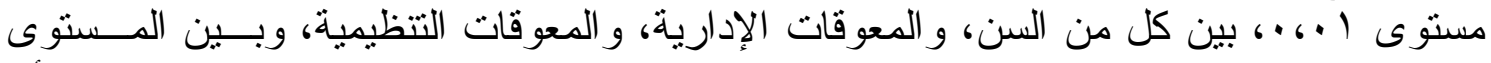

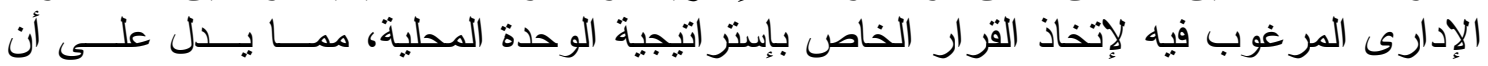

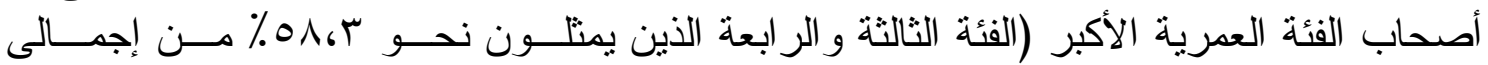

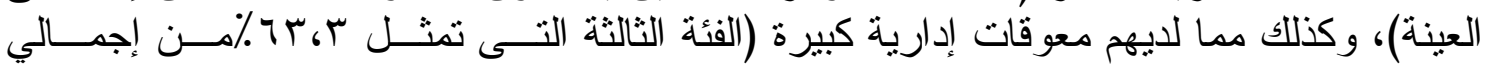

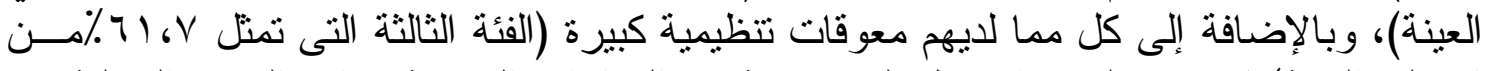

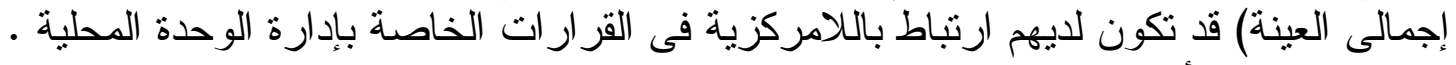

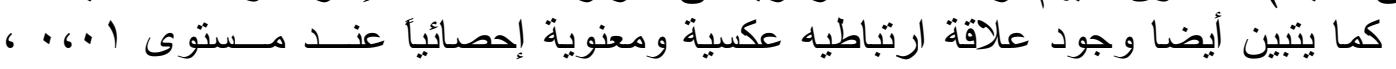

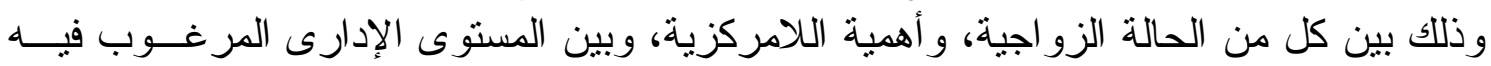

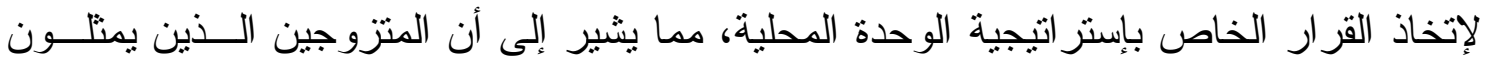

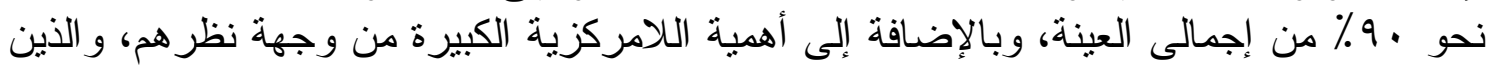

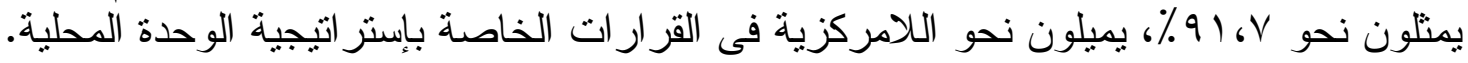

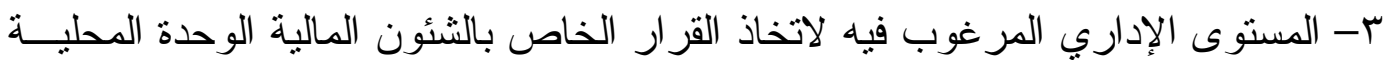

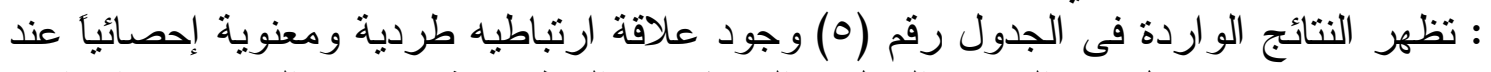

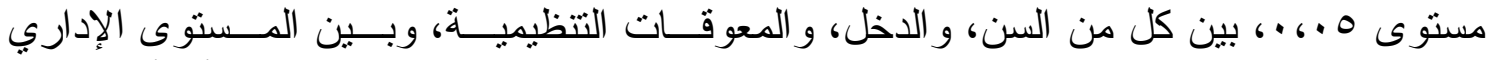

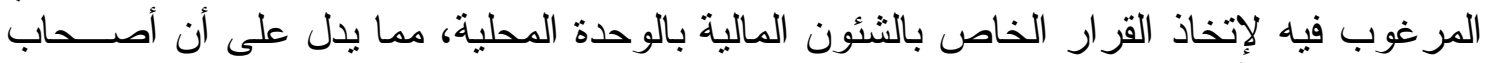

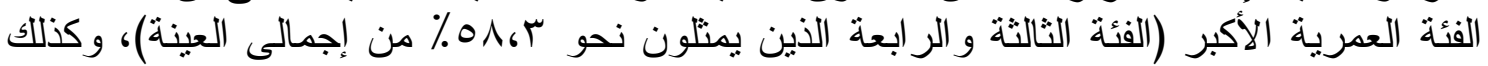

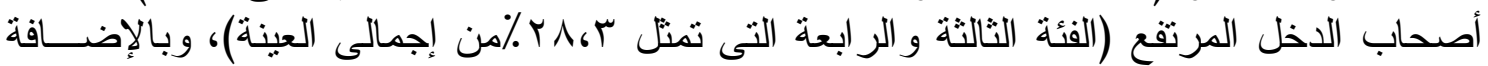

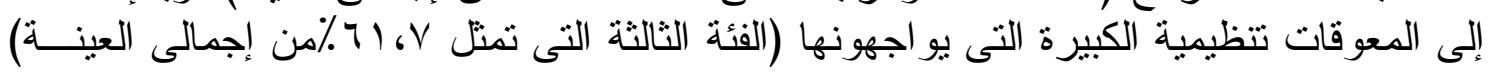
فقد تكون لديهم ميل كبير تجاه اللادركزية فى القرار ات الخاصة بالثئون تلفئ المالية بالوحدة المحلية.

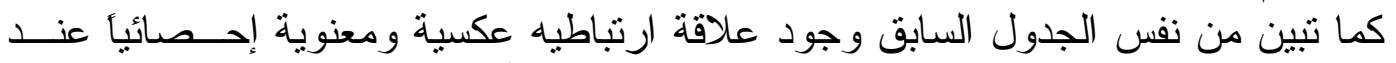

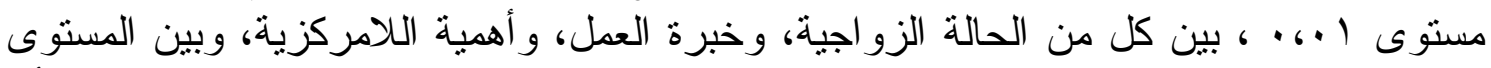

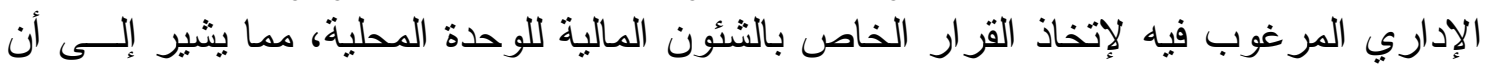

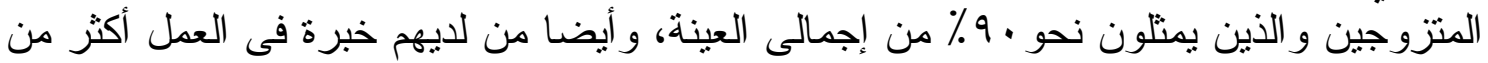

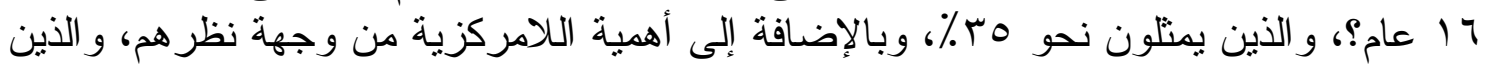


يمثلون نحو V، ا9 ٪، لديهم ارتباط باللامركزية فى القـر ار ات الخاصــة بإســتر اتيجية الوحــدة

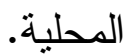

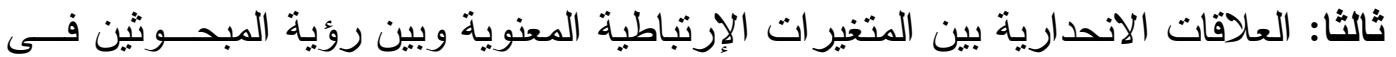

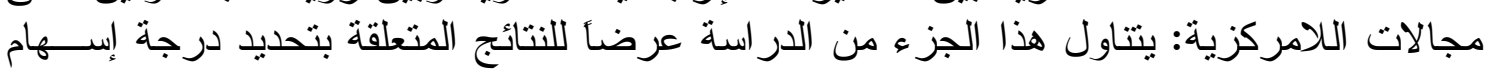

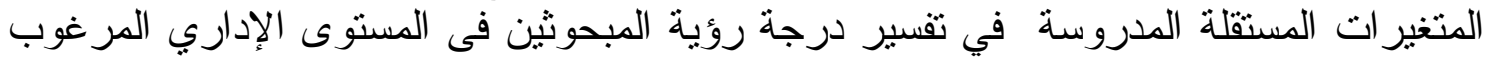

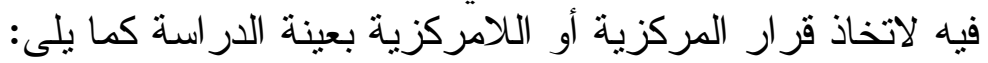

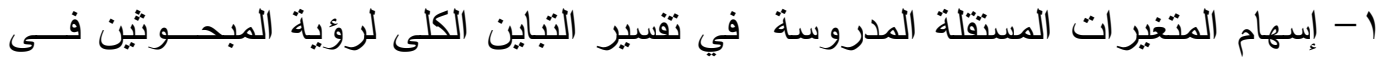
المستوى الإدارى المر غوب فيه لاتخاذ قرار إدارة الوحدة المحلية: 


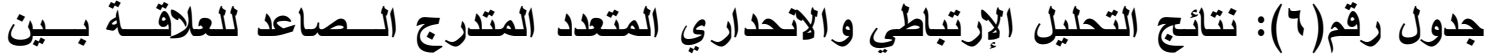

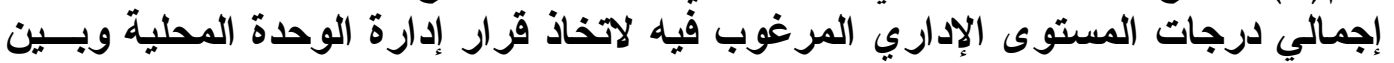

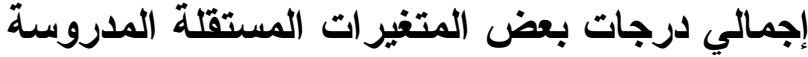

\begin{tabular}{|c|c|c|c|c|c|}
\hline قيمة (فحسة) & معامل التحديد & قيمة (تحسوبة & معامل الاتحدار & قيمة الثابت & الاختير المستقل \\
\hline \multirow{3}{*}{ 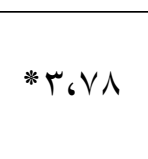 } & \multirow{3}{*}{$\% 17,1$} & $* Y_{6} \cdot 1$ & .601 & \multirow{3}{*}{1.611} & الاخل \\
\hline & & *Y.r.r- & $.6970-$ & & الانفتاح \\
\hline & & $* Y_{6}(T)$ & $.6 V Y T$ & & المعوقات التنظيمية \\
\hline
\end{tabular}

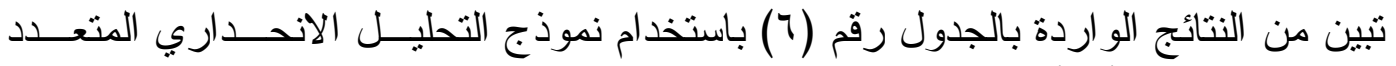

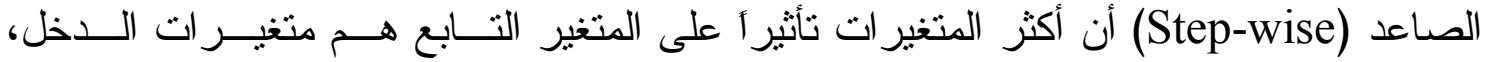

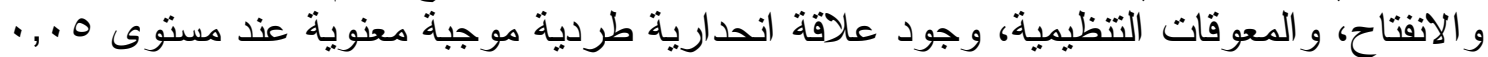

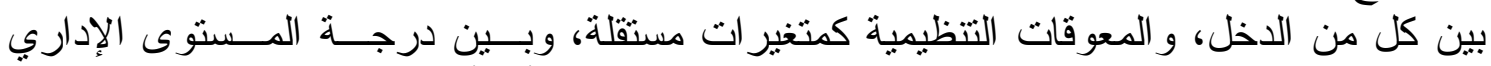

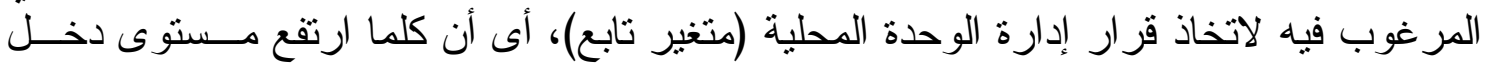

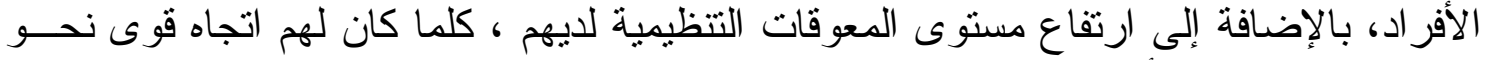

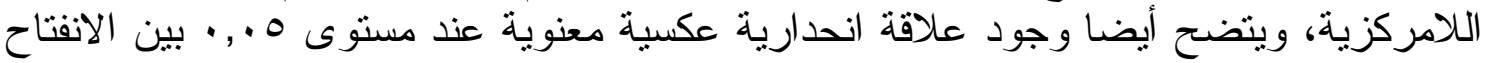

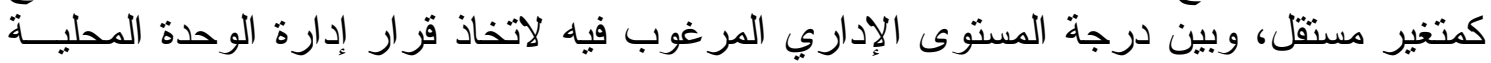

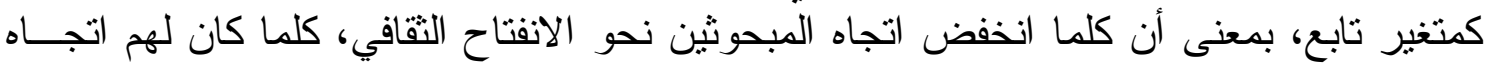

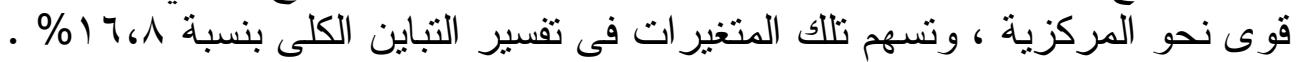

جدول رقم (V): نتائج التحليل الإرتباطي والاتحداري المتعدد المتدرج الــصاعد للعلاقــة بــين

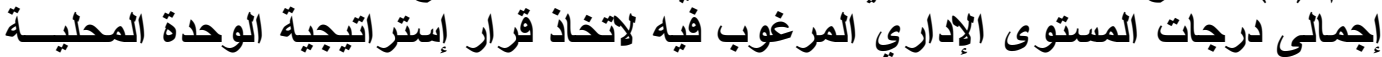

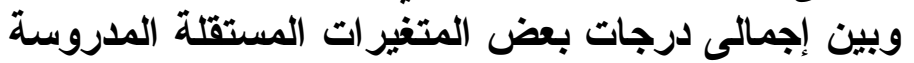

\begin{tabular}{|c|c|c|c|c|c|}
\hline قالمسمة (ف) & معامل التحديد & قيمة (تحسوبة & معامل الآحدار & قيمة الثابت & الاختير المستقل \\
\hline \multirow{2}{*}{$* * \Lambda_{6} \varepsilon r$} & \multirow{2}{*}{$\% Y_{\text {r }} \wedge$} & $* * Y_{6} \wedge$ 9 & . $6 \leqslant \Gamma \leqslant$ & \multirow{2}{*}{$V_{6} 09$} & السن \\
\hline & & $* * Y_{6} V Y$ & $.6 V \Gamma$ & & المعوقات التنظيمية \\
\hline
\end{tabular}

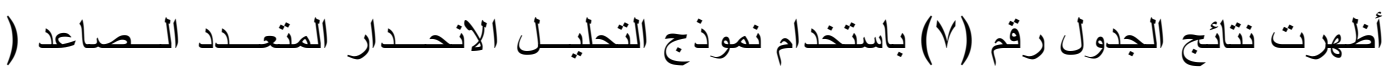

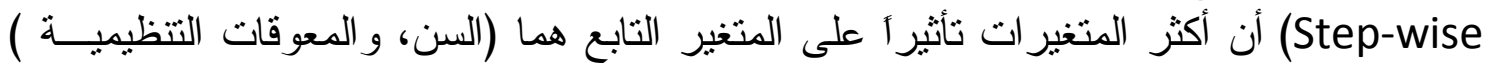

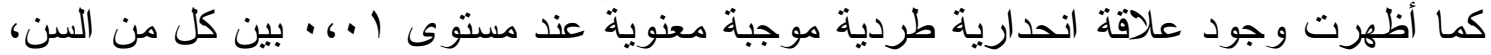

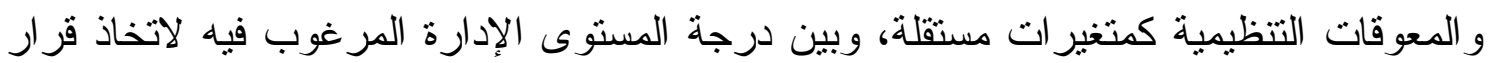

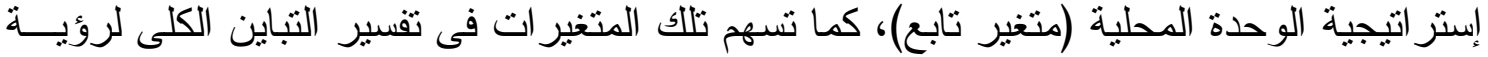

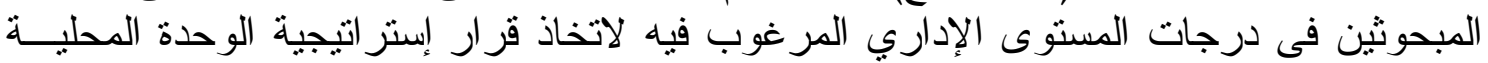

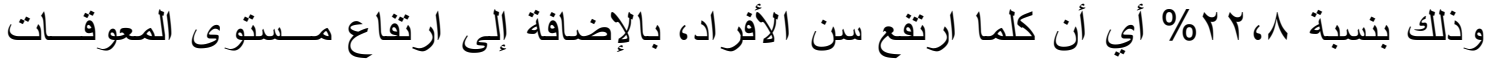

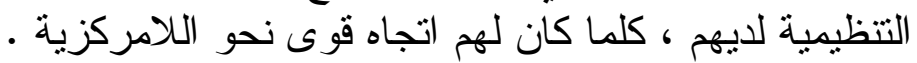




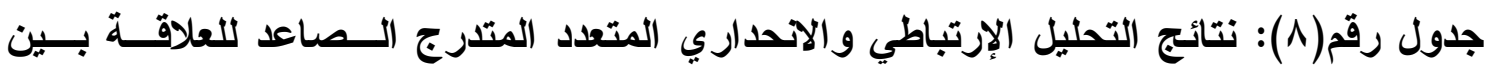

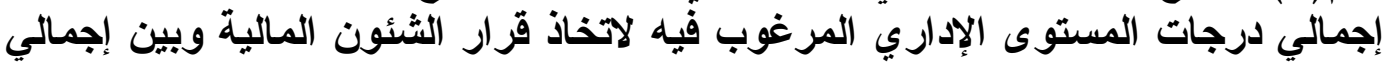
درجات بعض المتغيرات المستقلة المدروسية المارية

\begin{tabular}{|c|c|c|c|c|c|}
\hline قالمحسوبة (ف) & معامل التحديد & قالمحسوبة (ت) & معامل الآحدار & قيمة الثابت & الداخلية في التحليل \\
\hline \multirow{3}{*}{$* * \varepsilon, V)$} & \multirow{3}{*}{$\%$ Y. . 1} & $* Y_{6} 07$ & $.6 V T 4$ & \multirow{3}{*}{$11_{6} V_{0}$} & السن (ال) \\
\hline & & $*^{*} Y_{6} \cdot r_{\wedge}-$ & $r_{6} \wedge \varepsilon-$ & & علاقة الوحدة المحلية بالمنظة الأخرى \\
\hline & & $* Y_{6} \cdot V$ & $16 . r 1$ & & المعوقات التنظيمية \\
\hline
\end{tabular}

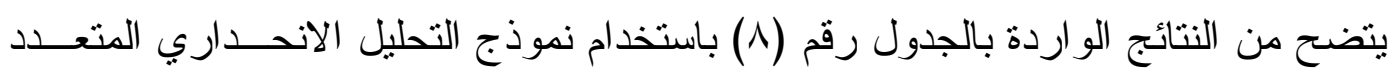

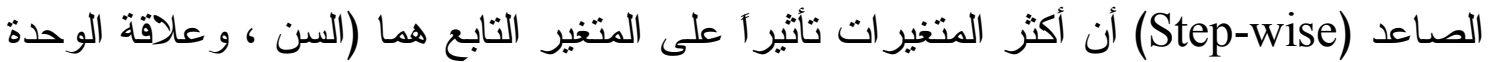

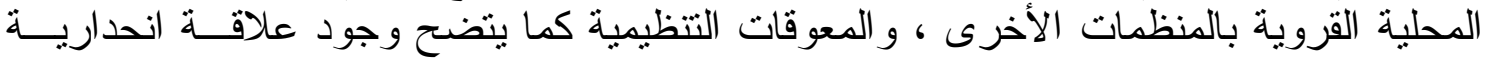

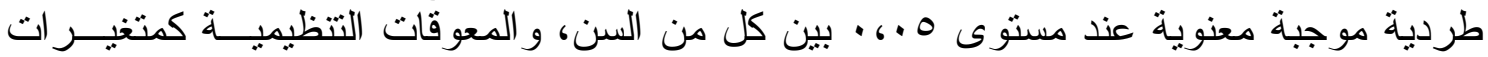

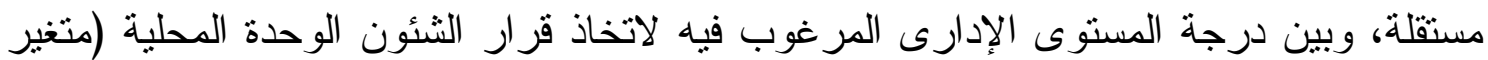

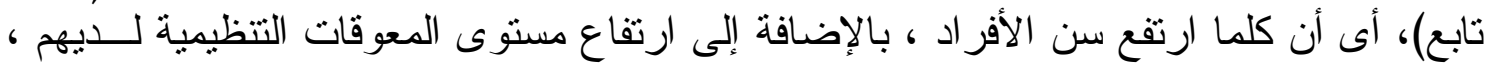

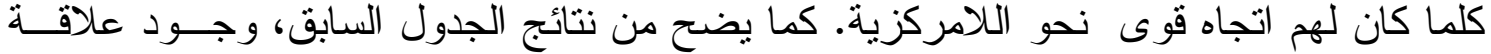

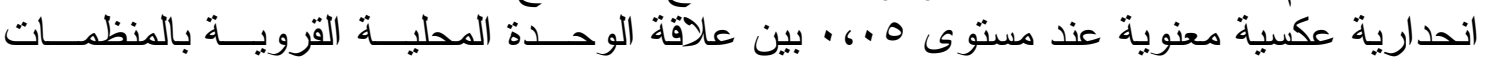

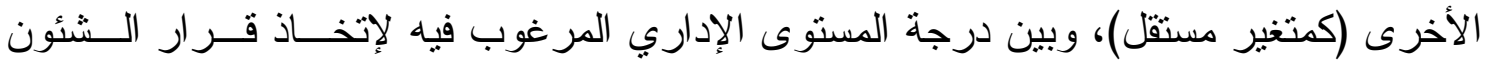

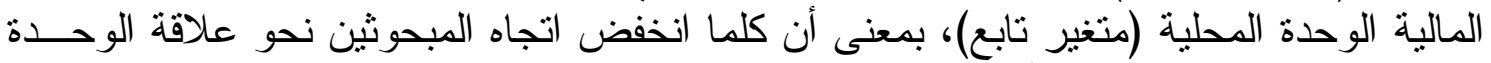

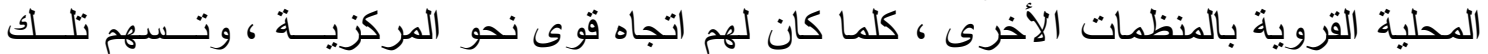

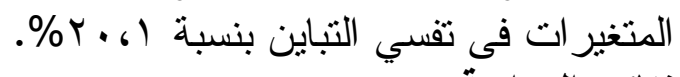

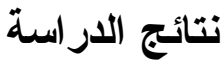
أبرز النتائج النى توصلت إليها الدراسة:

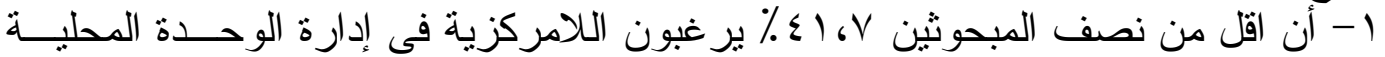

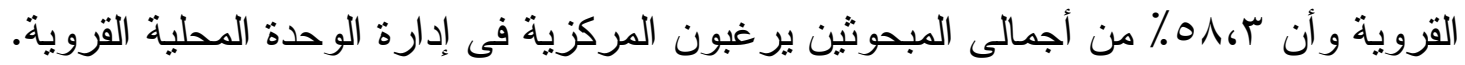

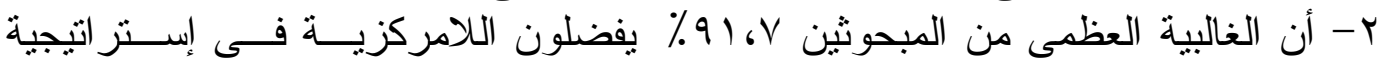

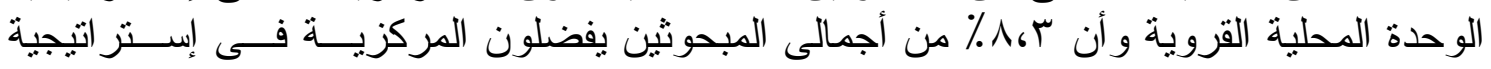

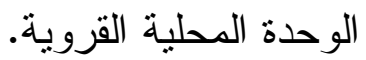

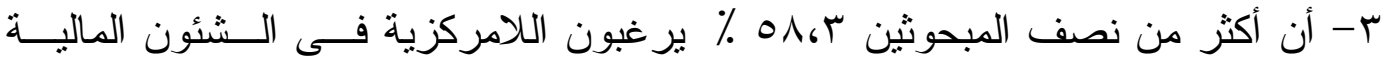

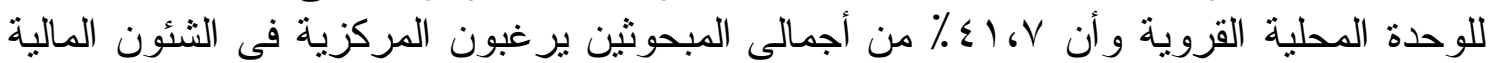

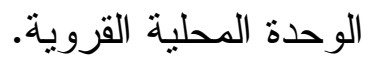

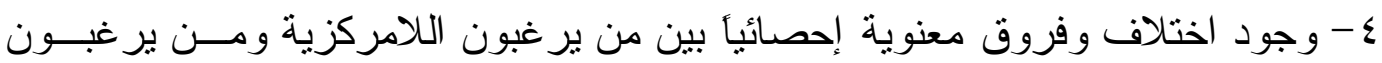

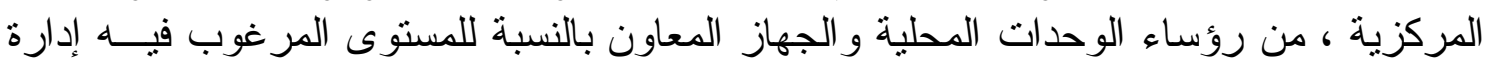

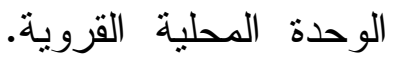

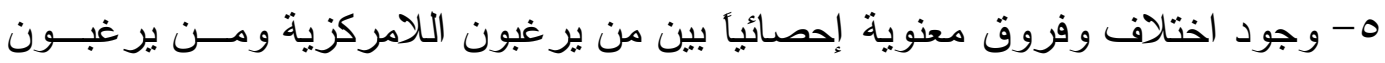

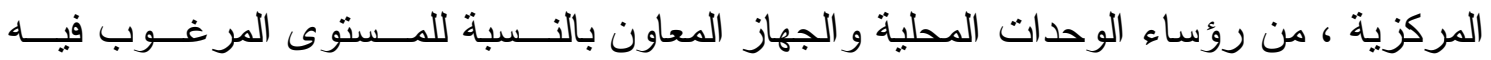
إستر اتيجية الوحدة المحلية القروية.

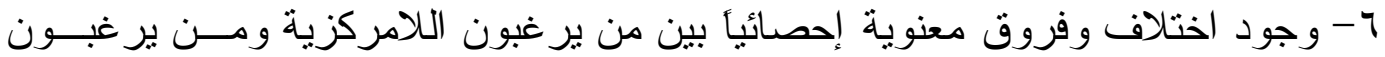

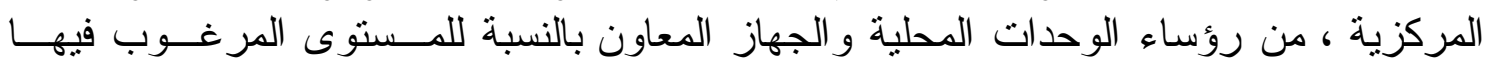
الثئون المالية للوحدة المحلية القروية. 


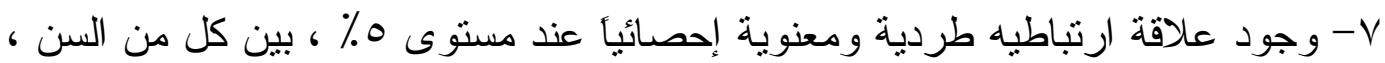

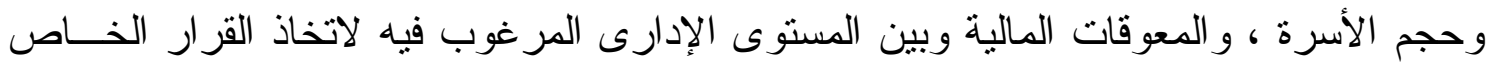

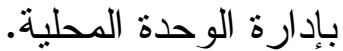

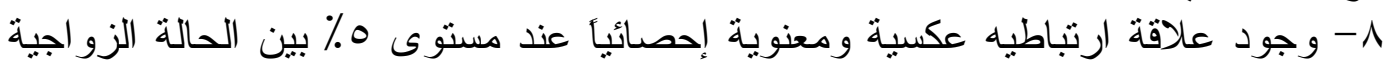

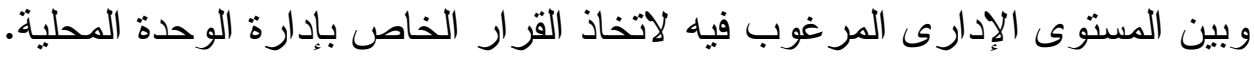

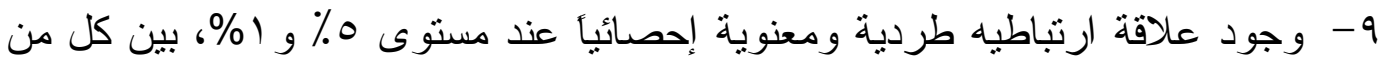

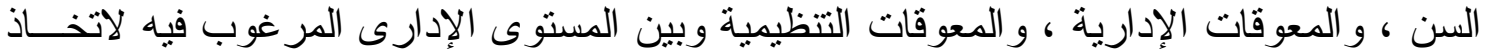
القرار الخاص بإستر اتيجية الوحدة الإداتة ، والمعلية.

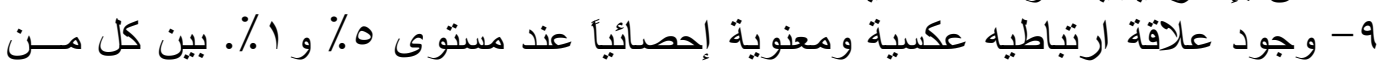

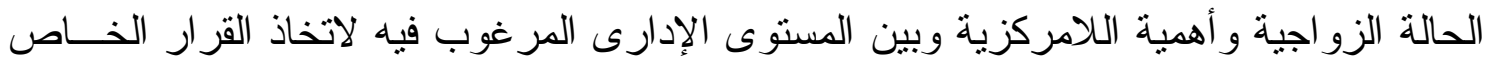
بإستر اتيجية الوحدة المحلية. • 1 - وجود علاقة ارنباطيه طردية ومعنوية إحصائياً عند مستوى ه ٪ ، بين كل من السن

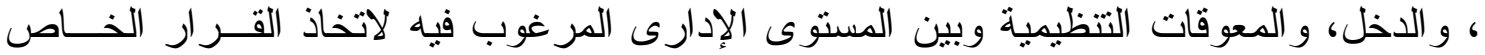
بالشئون المالية الوحدة المحلية.

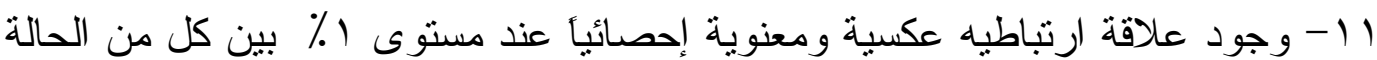

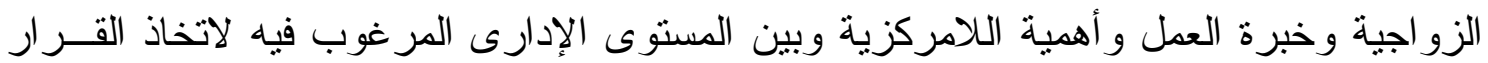
الخاص بالثئون المالية للوحدة المحلية.

الملخص و التوصيات

تعد اللامركزية احد الأدوات و الآليات لإدارة النظام المحلى، فالمحليـات هــــى الــصورة

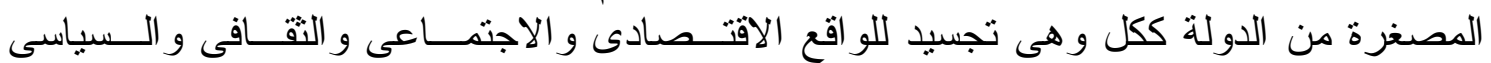

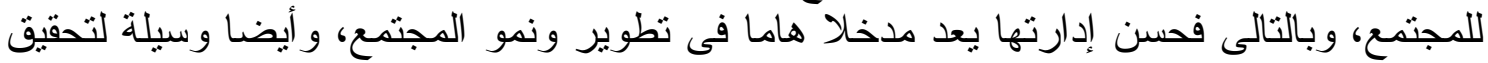

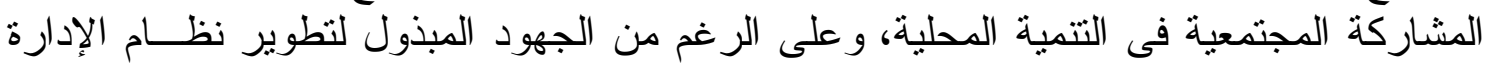

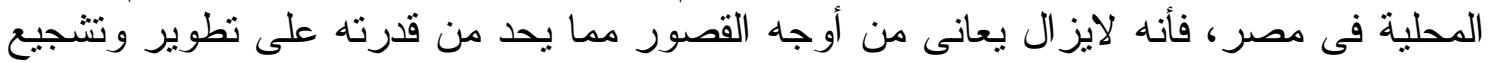
تطبيق اللامركزية، و الممارسة الديمقر اطية التى تحث على التى المشانه الماركة المجتمعية.

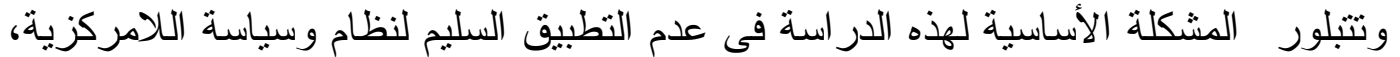

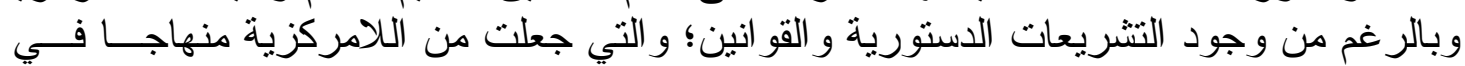

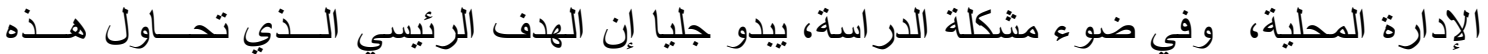

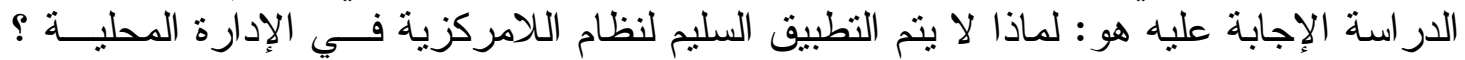

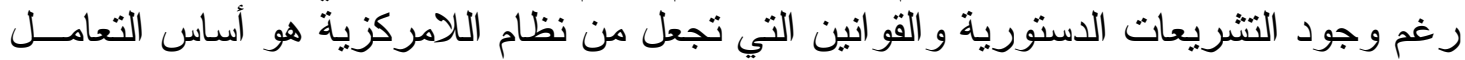
بين الحكومة المركزية و المسئولين المحلينين.

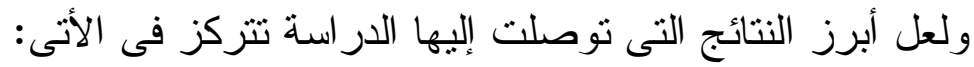

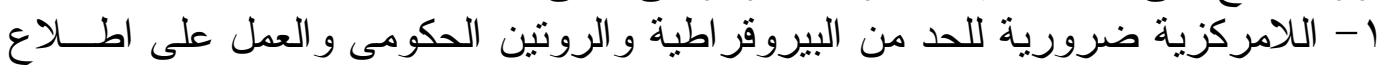

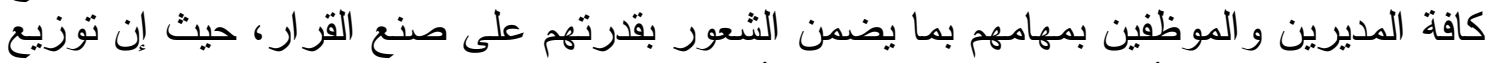

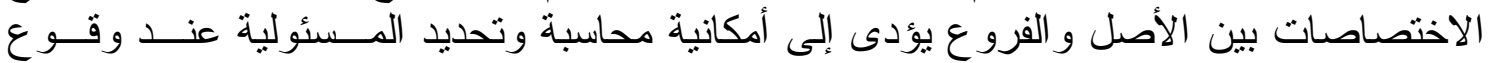
الأخطاء. r- اللادركزية تقود إلى مزيد من تحقيق الثفافية فى الإدارة المحلية وزيــادة المــشاركة

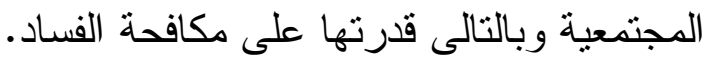

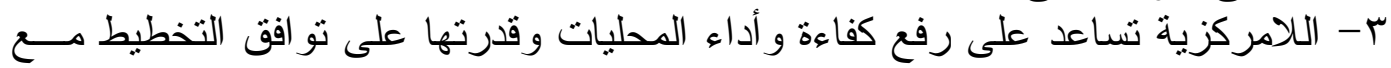

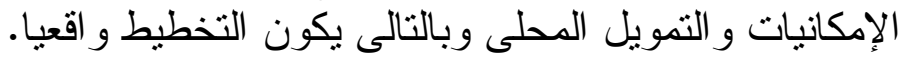

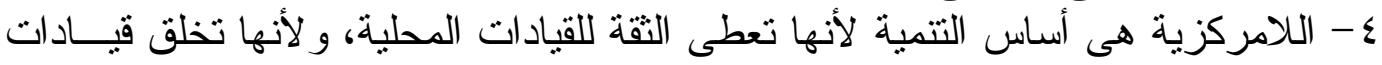
محلية متفهمة للو اقع المحيط بها سو اء كان و اقعا سياسيا او اجتماعيا أو اقتصاديا. 
ه- اللامركزية وسيلة لجعل الحكومة أكثر استجابة لاحتياجات المو اطنين ونقديمها بـشكل

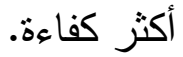

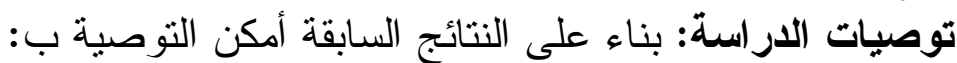

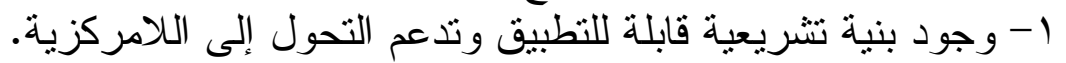

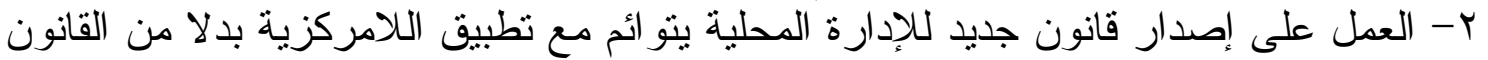

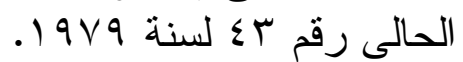

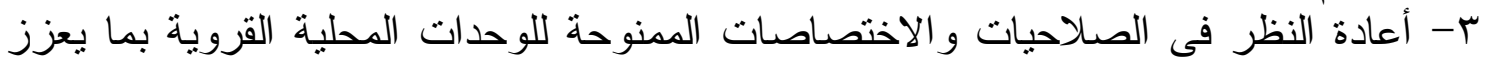
قدرتها على إدارة المر افق العادة العادية بالقرية. ع- زيادة المو ارد المالية للوحدات المحلية القروية للوصول اللوالية إلى تتمية محلية شاملة.

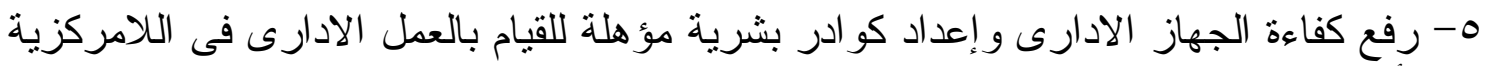
على أكمل وجهة. ؟- ترسيخ مبدأ الديمقر اطية وتوسيع قاعدة المشاركة المجتمعية في صنع القرار التتموي على

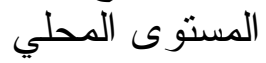

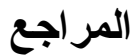

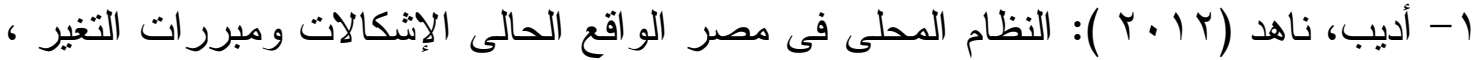

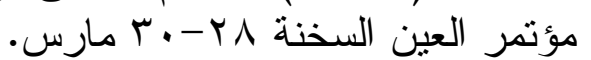

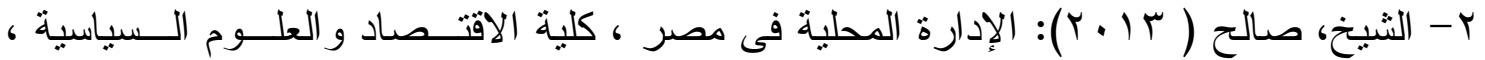

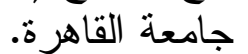

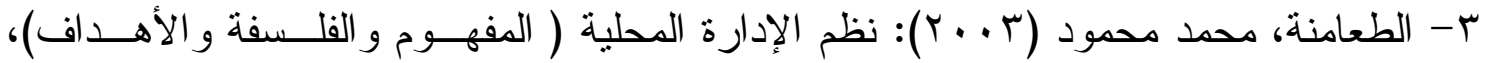

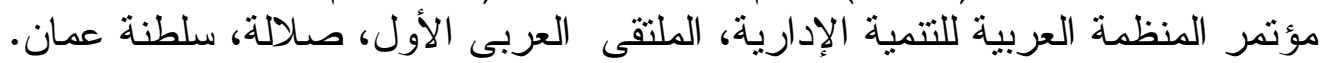

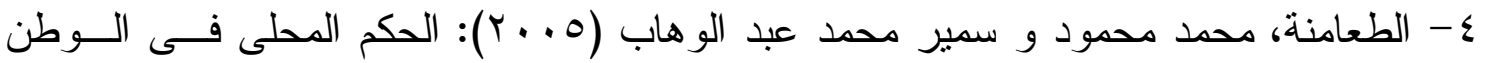
العربى و اتجاهات التطوير ، بحوث المعير المنظمة العربية للتتمية الإدارية.

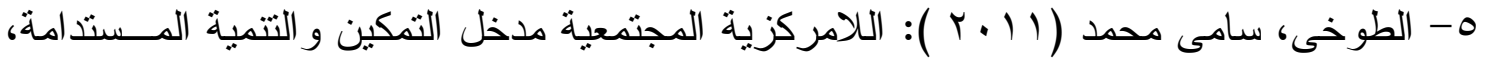

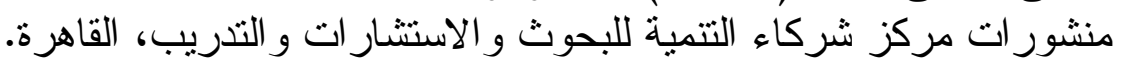

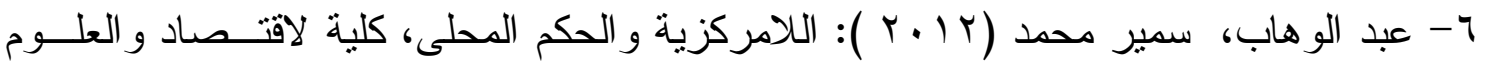
السياسية ، جامعة القاهرة.

7- Rodinelli, Dennis A. (1986): Extending Urban Services In Developing Countries, Public Administration and Development, 1986. 


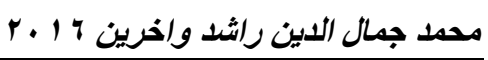

\title{
Towards Decentralization in local Rural Units in Menya Governorate: Challenges and Constraints
}

\section{G. E. Rashed ; A. M. Ali ; Asmaa B. Mohamed ; Hend H. Ali and M. A. Nady}

Department of Rural Sociology \& Agricultural Extension Fac. of Agriculture, Assiut University

\begin{abstract}
This research has been conducted to identify the challenges that hinder applying decentralization in local units of rural Minya Governorate. In addition, the study defines different types of local administration systems in Egypt in terms of the problems they face and mechanisms to overcome such problems. Moreover, the study analyzes various dimensions of decentralization and distinguishes between advantages and disadvantages of its application.

The study has applied the descriptive analytical research method. A sample of 60 respondents was randomly chosen from six village local units of Minya Governorate. Respondents of study are heads and/or associates of village local units.
\end{abstract}

The statistical analysis of data has been processed using SPSS. Percentages and frequencies have been used for descriptive analysis. Mann-Whitney test has also been used to check the significance differences between those who tend to accept decentralization and those who want centralization. Pearson simple correlation coefficient and Step-wise analysis were used to explain the discrepancy in the three investigated aspects of decentralization.

Followings are the important findings of study:

1. The percentage of respondents who prefer the decentralized management system at village local unit is $41.7 \%$ against 58.3 percent prefer centralization.

2. The most majority of respondents (91.7\%) prefer the decentralized strategy of village local units.

3. Financial decentralization of village local units is the preferred option by $58.3 \%$ of total respondents.

4. Using the Mann-Whitney test shows statistically significant differences at 0.01 level between those who want to apply centralization and those who tend to decentralization of the respondents in terms of management strategy and financial affairs of village local units.

It is concluded that the heads of village local units and associates prefer decentralization both in terms of the development of the local unit strategy and management of financial affairs while more than half of them prefer centralization in local administration.

Using Pearson simple correlation coefficient shows significant correlation relationships between the independent variables and the followings:

1. Desired management of the local unit at 0.05 level of significance in terms of the variables of age, marital status, family size and financial constraints.

2. Desired strategy of the local unit at 0.05 level of significance in terms of the variables of marital status and administrative obstacles, and at 0.01 level of significance in terms of the variables of age, the importance of decentralization and organizational obstacles. 
3. Desired financial affairs at 0.05 level of significance for the variables of age, marital status, income and organizational obstacles, and at 0.01 level of significance in terms of the variables of work experience and the importance of decentralization.

To interpret the total variation of respondents' viewpoints towards decentralization, Step-wiseanalys is proves that:

1. Significantly correlated variables of income, openness and organizational constraints help explain $16.8 \%$ of total disparity of change in the desired level of management at 0.05 level of significance.

2. The variables of age and income that are significantly correlated help explain $22.8 \%$ of the disparity of change in strategy of local unit at 0.01 level of significance.

3. The variables of age and the relationship of the local unit to other organizations help explain $22.8 \%$ of the disparity of change in decision making on financial affairs at 0.01 level of significance.

Followings are some of recommendations by study:

1. It is necessary to have a viable legislative structure that supports decentralization.

2. The current Law No. 43 of 1979 should be replaced by new one to be in line with desired decentralization.

3- Authorities granted to village local units need to be reconsidered in order to enhance their ability to manage public facilities in rural areas.

4. Much work should be devoted to increase the financial resources of village local units to achieve sustainable development.

5- It is important to enrich the administrative efficiency and prepare qualified human resources to carry out administrative work in decentralized manner. 